\title{
Spatial scale effect of surface routing and its parameter upscaling for urban flood simulation using a grid-based model
}

Article

Accepted Version

Cao, X., Lyu, H., Ni, G., Tian, F., Ma, Y. and Grimmond, C. S. B. (2020) Spatial scale effect of surface routing and its parameter upscaling for urban flood simulation using a gridbased model. Water Resources Research, 56 (2). e2019WR025468. ISSN 0043-1397 doi:

https://doi.org/10.1029/2019WR025468 Available at https://centaur.reading.ac.uk/88948/

It is advisable to refer to the publisher's version if you intend to cite from the work. See Guidance on citing.

To link to this article DOI: http://dx.doi.org/10.1029/2019WR025468

Publisher: American Geophysical Union

All outputs in CentAUR are protected by Intellectual Property Rights law, including copyright law. Copyright and IPR is retained by the creators or other copyright holders. Terms and conditions for use of this material are defined in the End User Agreement. 


\section{CentAUR}

Central Archive at the University of Reading

Reading's research outputs online 
Spatial scale effect of surface routing and its parameter upscaling for urban flood simulation using a grid-based model Xuejian $\mathrm{CaO}^{1}$, Heng Lyu ${ }^{1}$, Guangheng $\mathrm{Ni}^{1}$, Fuqiang Tian $^{1}$, Yu Ma ${ }^{1}$ and C. S. B Grimmond ${ }^{2}$

State Key Laboratory of Hydro science and Engineering, Department of Hydraulic Engineering, Tsinghua University, Beijing 100084, China; Department of Meteorology, University of Reading, Reading, UK Corresponding author: Guangheng Ni (ghni@tsinghua.edu.cn)

Key Points:

- Two parameters are proposed to achieve the quantitative depiction of surface routing features in an urban catchment.

- Coarser grids lead to underestimation of discharge for heavy rainfall events; whereas the effects are reversed for light rainfall events.

- A physically transferable scheme for key model parameters for different spatial resolutions is proposed, based on their routing features.

\section{ABSTRACT}

Urban catchments are characterized by a wide variety of complex juxtapositions and surface compositions that are linked to multiple overland flow paths. Their extremely high spatial heterogeneity leads to great sensitivity of hydrologic simulation to the scale variation of calculation units. Although extensive efforts have been made for investigating the scale effects and indicate its significance, less is understood of how routing features vary with spatial scales and further how the variation of routing features influences the hydrological response. In this paper, a grid-based distributed urban hydrological model is applied to study spatial scale effects ranging from 10 to $250 \mathrm{~m}$. Two parameters are proposed to quantitatively depict the routing features of overland flow specified for impervious and pervious areas. The results show that routing features are quite sensitive to spatial resolution. Large differences among simulations exist in the infiltration amounts attributed to the combined effects of the two routing parameters, which leads to opposite effects for both total flow volume and peak flow for various rainfall events. The relationship of the key model parameters at different spatial resolutions can be explicitly expressed by corresponding routing features. With this relationship, parameters transfer among different spatial scales can be realized to obtain consistent simulation results. This study further revealed the quantitative relationship between spatial scales, routing features and the hydrologic processes, and enabled accurate and efficient simulations required by real time flooding forecasting and land-atmosphere coupling, while fully taking the advantages of detailed surface information.

\section{Plain Language Summary}

Given the inherent complex underlying surface compositions and overland flow paths in urban areas, underlying high spatial resolution surface data eventually become necessary. Unfortunately, high resolution modelling in urban catchment is still challenging in terms of computational restricts, proper setting up of parameters etc., due to the high spatial heterogeneity. Practical simulation requirements often limit the use of high resolution models, as in the case of real time prediction of urban flooding, the coupling of land-atmosphere processes. Therefore, it is necessary to investigate the scale effects and its mechanism, and then to explore an accommodation approach to enable precise flooding prediction with a coarse model.

For grid-based and distributed hydrologic models, the mosaic method can basically eliminate the scale effects on the runoff generation process. However, the scale effects on overland flow routing remain insufficiently understood, and to help understand the scale effects, simulations were performed under five different resolutions, ranging from $10 \mathrm{~m}$ to $250 \mathrm{~m}$, for various rainfall events. Two physical parameters are introduced to quantify the scale effects on routing features. Three variables are concurrently calculated to assess the effects on modeling outputs. The results indicate that routing features are sensitive to changes in spatial resolution, which results in opposite effects on simulation results under different rainfall conditions. In conclusion, an accommodation approach is proposed based on the affecting mechanism.

\section{Introduction}

Compared with natural basins, hydrologic characteristics, such as slope, imperviousness, and soil water properties, exhibit higher spatial heterogeneity in urban catchments (Singh et al., 1997; Cantone et al., 2011; Zhou et al., 2017) due to the diverse underlying surface composition and complex microtopography, which consequently and significantly increase the complexity of routing paths. Therefore, modeling hydrological processes is challenging for urbanized areas with spatially variable hydrological characteristics, highly complicated overland flow paths and complex interaction between sewer systems and the overland surface (Salvadore et al., 2015; Wright et al., 2014a; Rodriguez et al., 2008; Leandro et al., 2016; McPherson et al., 1974). High spatial resolution data are crucial to provide a detailed depiction of the underlying surface and to capture the heterogeneity of key urban features in hydrological modeling (Petrucci et al., 2014). Although more and more high resolution data (Eggimann et al., 2017), e.g. topography, landuse/cover, are available, which provide catchment models with great details, high resolution modelling in urban catchment is still challenging in terms of computational restricts, proper setting up of parameters etc., due to the high spatial heterogeneity. Practical simulation requirements often limit the use of high resolution models, as in the case of real time prediction of urban flooding, the coupling of land atmosphere processes. Besides, conventional calibration approach can force coarse models to give a good performance by adjusting parameters, while it will become a great challenge for ungauged cities. Therefore, to facilitate flooding predictions in ungauged urban areas (Warsta et al., 2017) and improve real time flood warning in large urban areas, it is necessary to investigate issues of the extent and degree to which the spatial scale of calculation units affects simulation and, moreover, to address concerns about how to accommodate such effects (Fang, Z et al., 2016), enabling precise prediction with a coarse model instead of high resolution models. More importantly, as 
demonstrated by Ichiba et al. (2018) that forcing the model to give a better performance by changing its parameters is not reasonable for grid-based models because of their strong scale dependence, which further emphasized the importance of revealing the mechanism of scale effect.

The importance of enhancing the understanding of spatial scale effects was recognized in the early 1960s (Minshall et al., 1960; Amorocho et al., 1960). Thereafter, many researchers studied scale effects and investigated how spatial resolution affects hydrological modeling. For simulation based on drainage zones, varied resolution modeling was achieved by the aggregation and disaggregation of sub-catchments; different conclusions were obtained in different study areas. Metcalf et al. (1971) applied the Storm Water Management Model (SWMM) to the Northwood area in Baltimore and noticed that the coarser spatial resolution reduced the peak flow. However, Goldstein et al. (2016) found that the high-resolution model led to systematic underestimation of peak flows (Krebs et al., 2014), whereas the performance of the low-resolution model depended on the type of storms. In addition, Zaghloul (1981), Wood et al. (1988), Warwick et al. (1993), Park et al. (2008) and Elliott et al. (2009) conducted similar studies and found divergent spatial resolution effects. All the above-mentioned studies changed both the spatial variation of hydrologic parameters (e.g., saturated hydraulic conductivity (Ks) and feature width (W)) and the density of the network. The change in spatial variation of hydrologic parameters might lead to differences in infiltration and the length of overland flow, whereas the changed density of pipe networks leads to differences in the drainage capacity and the amount of network storage. Due to the coupled effects of different hydrologic processes, the scale effects can go in different directions (Ghosh et al., 2011). In contrast with simulation based on drainage zones, grid-based models can better capture the spatial heterogeneities of the surface and present detailed overland flow paths, which are widely adopted in urban flooding management.

The influence of spatial resolution on hydrological response is more pronounced for fully distributed and grid-based models (Ichiba, 2016), where the spatially variable hydrological characteristics and highly complicated overland flow paths can be explicitly reflected. Using the grid-based hydrologic modeling approach, Zhang et al., (1994) highlighted that the effect of grid scale on model performance is nonlinear: increasing resolution provides only marginal additional improvements when a given threshold is exceeded. Warsta (2017) carried out the automatic division of the subcatchments and noticed that an increase of spatial resolution led to more complex routing paths and increasing peak flow and runoff volume. Ichiba et al. (2018) proposed a two-step investigation framework to further illustrate the scale effects in urban distributed hydrological modeling but their results showed that increasing spatial resolution led to reduced peak flow and total flow. Concurrently, it was demonstrated in the above grid-based studies that coarser grids result in the loss of underlying surface information and the decrease in complexity of the overland flow paths between neighboring grids. To avoid the information loss of underlying surfaces, the mosaic method is feasible and effective (Krebs et al., 2014); it adopts the area weighting approach for the hydrologic parameters of each grid based on the finest available dataset. However, the potential scale effects attributed to the change of complexity of overland flow paths are insufficiently understood. Moreover, there remains the issues of how to quantitatively evaluate the routing features of overland flow and how to accommodate the routing-induced effects.

Directly connected impervious areas ratio (DCIAR), i.e., the ratio of impervious areas directly linked to the drainage system without the permeable zone cutting off (Boyd, 1994), has been demonstrated to be a better indicator than the total impervious areas ratio (TIAR) in much research (Yang, 2011; Burns, 2015) and is thus used in this study to depict the routing features of overland flow at different resolutions. In particular, during the early phase of storms with short-duration and low cumulative rainfall amounts, all runoff originated from the directly connected impervious areas, whereas unconnected impervious areas (UIA) contributed almost no flow at all (Schoener, 2017). Therefore, the hydrological model outputs are highly sensitive to the change in DCIAR (Hwang, 2017; Meierdiercks, 2010; Guan, 2015), and DCIAR estimation is critical to accurate runoff estimation (Sahoo, 2013). Despite its importance, in present practice DCIAR is simply chosen based on the type of land use, without a quantitative calculation approach.

This study aims to (1) quantitatively reveal the relationship between spatial scale, routing feature and hydrologic process, i.e. how routing features vary with spatial scales and further how the variation of routing features influences the hydrological response and (2) propose a physical based way to transfer key model parameters among different resolutions, enabling precise prediction with coarse models. Section 2 describes the study area and data, including distributed data of the underlying surface and hydrologic data of rainfall and river flow. The methodology for model simulation and the analysis of scale effects on both routing features and water balance are presented in the next section. Section 4 focuses on analysis of the mechanism of the spatial resolution effects, together with the description and verification of the proposed parameter upscaling approach under various rainfall conditions. Finally, Section 5 concludes with the findings of this paper.

\section{STUDY AREA AND DATA SETS}

\subsection{Study area}

This research was performed for a $3.3 \mathrm{~km}^{2}$ urban catchment located in the eastern Haidian District, Beijing, China, within the campus of Tsinghua University, as shown in Figure 1. The study area has typical underlying surface features of urban catchments, with various land cover types, such as buildings, pavement, roads, lawn and trees, and an imperviousness coefficient of approximately 50\%. In addition, dense drainage networks and artificial-lining river channels are distributed over the study area as main drainage facilities. Due to the nature of the surrounding borders, the entire study area is relatively independent from 
outside influences. Therefore, it is assumed that there is no surface water exchange between the study area and the surrounding areas, except for the incoming and outgoing discharges from rivers and pipes.

\subsection{Distributed data}

Due to the high complexity of both the land cover composition and spatial distribution in urban areas, multiple sets of highresolution data were collected. To capture the inherent heterogeneity for more accurate simulation, data integration was applied to high-resolution land cover data, detailed surface elevation data, road data and fine drainage network data. The land cover data were derived from the imagery of high-resolution satellite No.2 (an optical earth observation satellite in China, launched in 2014) with a vector format, classified into 7 types: building, pavement, road, water, grass, shrub and tree. The roads and river channels were extracted from the data set to produce a topographic distribution map for routing analysis use. Elevation data at nearly 30,000 points were measured and used to generate the DEM of the study area. The drainage network data, including pipe spatial distribution and dimensions, were obtained from the administration department of the university; the total length of pipes exceeded 25 kilometers.

\subsection{Hydrologic data}

As one of the main driving factors of hydrological models (Yang et al., 2016; Wright et al., 2014b; Zhou et al., 2018), rainfall data with temporal resolution higher than five minutes are necessary in urban catchments (Berne et al., 2004). To measure the fine rainfall process, a disdrometer (OTT Parsivel ${ }^{2}$, made in Kempten, Germany) was installed at the center of the study area (as shown in Figure 1) and provided rainfall data with a temporal resolution of 1 minute. Although the spatial variability of precipitation has a considerable impact in large urban catchments (Umakhanthan et al., 2005; Yang et al., 2015), precipitation is often assumed to be spatially uniform in small catchments (Goodrich et al., 1995; Einfalt et al., 2004). Considering the relatively small study area of $3.3 \mathrm{~km}^{2}$ and the near central location of the disdrometer, the rainfall at a single point is representative of the entire study area (Berne et al., 2004). From the rainfall data available, 18 representative events were selected for this study, with total rainfall depths ranging from $5 \mathrm{~mm}$ to $200 \mathrm{~mm}$ and rainfall durations varying from $3 \mathrm{~h}$ to $59 \mathrm{~h}$, which cover the major rainfall types in Beijing (Yang et al., 2013). The main features of the selected rainfall are summarized in Table 1.

Four events that could represent the actual rainfall conditions of different magnitudes were selected (as shown in Table 1) to study the parameter upscaling scheme below. Given that their rainfall temporal patterns differ from each other (Figure A1), another four designed events with varying rainfall amounts but a uniform pattern (the same as E170714, a relative moderate and typical rainfall event) were also adopted in the study to test the scheme without the effects of rainfall pattern.

A noncontact radar flowmeter for open channels, (HZ-SVR-24Q, made in Shanghai, China), was installed on the river near the outlet of the study area to measure the discharge. First, the flow velocity of water surface was measured based on the Doppler Effect, and flow rate was then derived considering the water depth and cross section from a fluid mechanics model.

\section{METHODOLOGY}

\subsection{Model Setup}

To represent the high heterogeneity of urban catchments, a grid-based distributed urban hydrological model named REDUS (routing-enhanced detailed urban stormwater model) was developed (Lyu, 2018). Taking advantage of the urban hydrological model (Pan et al., 2012) and the multilevel urban flooding model (Li et al., 2016), REDUS uses a four-layer structure, including surfaces, road networks, pipe networks, and river networks. Each grid is subdivided into pervious and impervious areas, and direct runoff is determined by subtracting interception and infiltration from the rainfall. If the grid contains roads, the generated runoff will flow into the road network; otherwise, it will flow onto adjacent grids according to the flow direction determined by the D8 algorithm (Passalacqua et al., 2010; Gangodagamage et al., 2011) based on underlying surface elevation. After flowing into the road network, the generated runoff is further routed into the sewer network through neighboring manholes and then flows into the river. Following this calculation flowchart yields a more realistic description of the hydrological process in an urban catchment during flooding.

The model is calculated for three components: surface runoff, overland flow, and sewer and river flow. The Green-Ampt equation (Green and Ampt, 1911; Brakensiek et al., 1977) is applied to simulate the infiltration process at each grid, and the onedimensional dynamic wave approach is used to simulate the routing process in sewer and river systems. Overland flow calculation is divided into two steps: flow inside the grid and routing between different grids. The nonlinear reservoir algorithm (Rossman et al., 2015) is selected to compute the overland flow inside the grid with proper feature width and slope, and the routed flow is then uniformly distributed over the downstream grid.

For the distributed urban hydrological model, parameterization is a critical step before application (Sun et al., 2012), and most of the parameters are sensitive to model scale (Krebs et al., 2013). Extensive studies have shown that the sensitive parameters in urban hydrological modeling include feature width, imperviousness, the Manning coefficient, and slope, among others (Krebs et 
al., 2013; Kocyigit et al., 2017). In this study, REDUS is grid-based and the feature width is directly set to the grid size. The area weighting approach is adopted for other parameters, i.e., for each grid of different spatial resolution, the slope and imperviousness are directly calculated from the finest elevation data and the detailed underlying surface information. In this way, the mean parameter values for different spatial resolutions can be maintained. The parameters left for calibration are initial loss, soil infiltration parameters and Manning coefficients for overland flow and sewer drainage.

Calibration was conducted for six distinct rainfall events at 10-m spatial resolution. The Nash-Sutcliffe efficiency (NSE) (Nash and Sutcliffe, 1970), correlation coefficient and peak flow relative error were selected to evaluate the goodness-of-fit between simulated and observed results. The parameters related to the underlying surface and the parameters related to infiltration and drainage system are summarized in Table 2 and Table 3, respectively. Given the limited available soil data and the relatively small study area, soil properties were assumed to be uniform throughout the area. Considering both the good drainage conditions, even under the lawns, and the lower groundwater level (more than $20 \mathrm{~m}$ ), a relatively high value similar to that of Rosa (2015) was set for the initial deficit. As shown in Figure 2, the observed flow dynamics are very well reproduced, with NSEs of more than 0.9 .

To investigate the spatial effect, data sets were prepared for five different spatial resolutions ranging from $10 \mathrm{~m}$ to $250 \mathrm{~m}$, whereas other input data and parameters, such as rainfall events and sewer networks, were kept the same. Based on the mosaic method, the original high resolution underlying surface data were discretized into regular grids of different sizes. The model simulations were run for varying spatial resolutions of $10 \mathrm{~m}, 30 \mathrm{~m}, 50 \mathrm{~m}, 100 \mathrm{~m}$ and $250 \mathrm{~m}$, corresponding to 32,640, 3618, 1304, 333 and 51 calculation grids, respectively. The calibrated case of the finest resolution $(10 \mathrm{~m})$ was then taken as the control case; results for other resolutions were compared with the control case results, and the biases indicated how large the scale effects were.

\subsection{Assessment of Scale Effects on Model Parameters}

The parameters roughly affect model outputs in two aspects: runoff generation and runoff routing. For runoff generation, although the mosaic method is adopted, different grid resolutions may produce effects via model parameters, including depression, imperviousness, slope, and Manning's coefficient. On the other hand, runoff routing characteristics, which reflect the flow path features between grids and affect model outputs, also vary with grid size. In particular, for urban catchments with underlying surfaces of high complexity, the runoff routing paths of different grid sizes are usually quite different.

To reflect the routing features of overland flow at different resolutions, two physical parameters related to impervious and pervious areas (i.e. $P^{i m p}$ and $P^{p}$ ) were introduced in this study. For impervious areas, different flow paths are expressed by differences in $P^{i m p}$, reflecting the value of DCIAR. For example, the runoff of some impervious areas can be directly routed into the drainage system or routed to the adjacent grids with impervious ratios of $100 \%$ and then further routed into drainage systems without additional infiltration, whereas runoff from other impervious areas may flow onto permeable areas and infiltrate along the way. As demonstrated in Figure 3, a certain percentage of the runoff from an impervious area flows onto the downstream pervious areas, which is assumed to be related to the impervious ratio of downstream grids.

In this study, an iterative algorithm based on routing path (IABRP) was proposed to compute $P^{i m p}$. According to the overland flow paths of every grid, the IABRP calculation will continue until the runoff from the impervious area eventually flows into the drainage system. The $P^{i m p}$ for a specified grid and the entire study area are written as:

$$
\begin{aligned}
& P_{i}^{i m p}=\prod_{j=0}^{k} I m p_{i j} \\
& P^{i m p}=\frac{\sum_{i=1}^{m} P_{i m}^{i m p}}{m}
\end{aligned}
$$

where $P^{i m p}{ }_{i}$ is the directly connected impervious areas ratio of the $i^{\text {th }}$ grid; $I m p_{i j}$ is the impervious ratio of the $j^{\text {th }}$ grid onto which the $i^{t h}$ grid runoff flows; $P^{i m p}$ is the directly connected impervious areas ratio of the whole study area; $k$ is the grid number of the runoff generated from the $i^{\text {th }}$ grid that will flow across before reaching the drainage system; and $m$ is the total number of grids in the model at a specific spatial resolution.

For pervious areas, runoff flows in the same manner as for impervious areas. Runoff from some permeable area can be directly routed into the drainage system, whereas runoff from others may flow onto adjacent grids and finally flow into the drainage system, which leads to larger $P^{p}$ (i.e. longer average routing length on permeable areas) and results in more infiltration. IABRP is simultaneously applied to the calculation of both $P^{i m p}$ and $P^{p}$. In the calculation of $P^{p}$ of one grid, not only the routing path length but also the ratio of the rainfall amount falling on the pervious area to the total rainfall (i.e., the ratio of pervious area to grid area) are taken into account by the area weighting approach. In the ideal situation, where the drainage system is sufficiently dense, the runoff from every grid is directly routed into the drainage system; in this case the $P^{p}{ }_{\min }$ can be computed by equation (3). However, in most cases the runoff from permeable areas flows to adjacent grids and then to another grid, which repeats many times until the drainage system is reached. It is difficult to compute the actual $P^{p}$ because it is affected by the spatial 
distribution of both surface topography and rainfall intensity. For a specific grid, the runoff generated from its permeable area can be divided into three parts: infiltration along the routing path, flow through all permeable areas into the drainage system, and flow diverted to adjacent impervious areas. To simply quantify the complex effects of routing between adjacent grids, this study assumes that all runoff from one permeable area has the same routing length, which is set to the total pervious area length along the overland flow path. In general, this assumption will overestimate the $P^{p}$ and lead to an increase in the $P^{p}$ differences with spatial resolution. Taking into account the routing between different grids under the longest path condition, $P^{p}{ }_{\max }$ is computed using equation (4):

$$
\begin{gathered}
P_{\text {min }}^{p}=\frac{l \times \sum_{i=1}^{n}\left(1-i m p_{i}\right)^{2}}{\sum_{i=1}^{n}\left(1-i m p_{i}\right)} \\
P_{\text {max }}^{p}=\frac{l \times \sum_{i=1}^{n}\left[\left(1-i m p_{i}\right) \times \sum_{j=0}^{k}\left(1-i m p_{i j}\right)\right]}{\sum_{i=1}^{n}\left(1-i m p_{i}\right)}
\end{gathered}
$$

where $P^{p}{ }_{\min }$ is the average routing length on the permeable area without considering routing between different grids, $\mathrm{m}$; the constant $l$ is the grid size, $\mathrm{m} ; i m p_{i}$ is the impervious ratio of the $i^{\text {th }}$ grid; $l \times\left(1-i m p_{i}\right)$ is the pervious area length in the grid, $\mathrm{m}$; $P^{p}{ }_{\text {max }}$ is the average routing length on the permeable area considering routing between different grids under the longest path condition, $\mathrm{m}$; and $i m p_{i j}$ is the impervious ratio of the $j^{\text {th }}$ grid onto which the $i^{\text {th }}$ grid routes.

\subsection{Evaluation of Scale Effects on Model Outputs}

Detailed water balance analysis was performed for the study area to identify the major effects of spatial resolution on general model outputs. In addition to the river there are a few other drainage outlets where water flows out that need to be considered for water balance closure. The amount of evaporation is small during the rain period and can be ignored. The resulting water balance equation is described as:

$$
P=Q_{r}+Q_{o}+I+S_{d}+S_{s}
$$

where $P$ is rainfall, $\mathrm{m}^{3} ; I$ is infiltration, $\mathrm{m}^{3} ; Q_{r}$ is the flow out of the river, $\mathrm{m}^{3} ; Q_{o}$ is the flow out of other outlets, $\mathrm{m}^{3} ; S_{d}$ is the amount of water stored in the drainage system, $\mathrm{m}^{3}$; and $S_{s}$ is the amount of water stored in the surface depression, $\mathrm{m}^{3}$.

In addition, three indicators related to river discharge, the relative error of total flow (RET), the relative error of peak flow (REP) and the relative error of infiltration (REI), are selected to quantify the effect of spatial resolution on model outputs; each is calculated as follows:

$$
\begin{aligned}
& \text { RET }=\frac{T F-T F_{10}}{T F_{10}} \\
& \text { REP }=\frac{P F-P F_{10}}{P F_{10}} \\
& \text { REI }=\frac{I-I_{10}}{I_{10}}
\end{aligned}
$$

where $T F$ is the total flow at the river outlet, $\mathrm{m}^{3} ; T F_{10}$ is the total flow at the river outlet at $10 \mathrm{~m}$ resolution, $\mathrm{m}^{3} ; P F$ is the peak flow at the river outlet, $\mathrm{m}^{3} / \mathrm{s} ; P F_{10}$ is the peak flow at the river outlet at $10-\mathrm{m}$ resolution, $\mathrm{m}^{3} / \mathrm{s} ; I$ is the amount of infiltration, $\mathrm{m}^{3}$; and $I_{10}$ is the amount of infiltration at $10-\mathrm{m}$ resolution, $\mathrm{m}^{3}$.

\subsection{Parameter Upscaling Approach}

Spatial resolutions affect model outputs via runoff generation and routing processes. The routing-related effects can be reflected by the $P^{i m p}$ and $P^{p}$ values of corresponding grid size. Therefore, a good match can be reached between model outputs of coarser grids with that of the finest grid by keeping the values of $P^{i m p}$ and $P^{p}$ steady. $P^{i m p}$ and $P^{p}$ are closely related to the spatial resolution, while their values or effects on hydrologic processes can be influenced by the key hydrologic parameters in the model. Based on this idea, a parameter upscaling approach is proposed to derive parameters for coarser resolution based on underlying surface features that are directly obtained from fine-resolution data, given that the relationship exists among $P^{i m p}, P^{p}$ values and corresponding grid sizes.

\subsubsection{Matching via $P^{i m p}$}

In the REDUS, Percent Routed $\left(P_{r}\right)$ is a user-specified input parameter for internal rerouting with a default value of zero. As a specified fraction of the runoff from a grid's impervious area that can be set to flow onto its permeable area, $P_{r}$ is then used to correct the insufficient routing for simulation with coarser grids. This is realized via an improved IABRP: for each grid size simulation, $P_{r}$ is adjusted to obtain the same $P^{i m p}$ as that at the finest resolution so that the same runoff as that at the finest resolution is directly routed into the drainage network. The relationship between $P^{i m p}$ and $P_{r}$ is as follows: 


$$
\begin{gathered}
P_{i}^{i m p}=\prod_{j=0}^{k} \operatorname{Im} p_{i j} \times\left(1-P_{r}\right)^{(k+1)} \\
P^{i m p}=\frac{\sum_{i=1}^{m} P^{i m p}{ }_{i}}{m}
\end{gathered}
$$

where $P_{r}$ is the value of Percent Routed; $P^{i m p}{ }_{i}$ is the directly connected impervious areas ratio for a specific grid with specific $P_{r}$ value; $P^{i m p}$ is the directly connected impervious areas ratio for the entire study area with grids of different $P_{r}$ values; $k$ is the grid number of the runoff generated from the $i^{\text {th }}$ grid that will flow across before reaching the drainage system and $m$ is the total number of grids in the model under a specific spatial resolution.

\subsubsection{Matching via $P^{p}$}

For each grid, the nonlinear reservoir algorithm (Rossman et al., 2015) is adopted to estimate the overland flow process, written as the following equation:

$$
q=\frac{W S^{\frac{1}{2}}}{A n}\left(d-d_{s}\right)^{\frac{5}{3}}
$$

Where $q$ is the flow rate per unit of surface area, $\mathrm{m} / \mathrm{s} ; W$ is the sub-catchment feature width, $\mathrm{m}$;

$S$ is the sub-catchment slope; $d$ is the water depth, $\mathrm{m} ; d_{s}$ is the depth of depression storage, $\mathrm{m} ; A$ is the area of grid, $\mathrm{m}^{2} ;$ and $n$ is Manning's coefficient. For regular grids, equation (11) can be rewritten as follows:

$$
q=\frac{S^{\frac{1}{2}}}{L n}\left(d-d_{s}\right)^{\frac{5}{3}}
$$

Where $L$ is the length of the overland flow in a grid, $\mathrm{m}$. The equation indicates that $q$ decreases as $L$ increases due to longer infiltration duration and larger infiltration amounts for soil of the same hydrological properties. Therefore, to match the model outputs with the control case in terms of peak flow and total flow, $P^{p}$-related correction are essential. From equation (12), Manning's coefficient $(n)$ plays the same role as $L$, and the $P^{p}$-related correction can thus be achieved by adjusting the $n$ of pervious areas after $P_{r}$ is determined to obtain a better-matched model output. However, it is a great challenge to calculate $n$ by an equation due to the indeterminate value of the actual $P^{p}$, which is affected by both routing paths and rainfall intensity. Therefore, first we decided the reasonable range of $n$ values for different resolutions based on the calculated $P^{p}{ }_{\min }$ and $P^{p} \max$. Then, the variation trend of $n$ under varying rainfall conditions were investigated in the derived reasonable range.

RESULTS AND DISCUSSION

4.1 Effect of Spatial Resolution on Routing Features

As shown in Figure 4, variations of the key runoff parameters, such as imperviousness, depression, roughness and slope, are obviously reduced with lower spatial resolution, although the mean values remain steady due to the mosaic method used in the upscaling. This further explains that variation in spatial resolution causes little simulation discrepancy during the runoff generation process (Krebs, 2013; Krebs, 2014; Goldstein, 2016).

Figure 5 shows the spatial resolution effects on grid routing features calculated by IABRP. Although the total impervious area ratios are the same for different resolutions, both $P^{i m p}$ and $P^{p}$ decrease with finer resolutions. Finer resolution data can describe the routing path in more detail, which lead to smaller $P^{i m p}$ and $P^{p}$ and thus results in more runoff generated on impervious areas flowing onto permeable areas and less infiltration on pervious areas, respectively. When the spatial resolution is as coarse as 100 $\mathrm{m}, P^{\text {imp }}$ nearly equals TIAR, which means that the impervious areas are totally and directly connected to the drainage system. In terms of the gap between $P^{p}$ min and $P^{p}{ }_{\max }$, a larger difference is shown at finer spatial resolution due to the more complicated routing path. With decreasing spatial resolution, the gap will disappear gradually. In general, the actual $P^{p}$ values under different rainfall conditions should fall between the two curves.

\subsection{Model Performance at Different Spatial Resolutions}

Simulations were conducted for the selected 18 rainfall events from year 2012 to 2017, with grid sizes of 10, 30, 50, 100 and 250 $\mathrm{m}$. Taking the simulation result for 10-m resolution as the base case, errors/biases were calculated to evaluate the effect of spatial resolution on model performance. Regarding the water balance items, Figure 6 shows that the simulation bias in infiltration amount and river flow are more significant, with similar magnitudes, than the other water balance items. Moreover, the tendency of the simulation bias of river flow remains very consistent with that of infiltration amount, which indicates that the change in river flow can be mainly attributed to the change in infiltration.

Figure 7 further demonstrates the spatial resolution effects on model outputs for various rainfall events of different magnitudes and temporal patterns. Obvious bidirectional effects can be found on total flow, peak flow and the amount of infiltration, i.e. the 
scale effects are opposite under heavy and small rainfall conditions. For light rainfall events, $P^{p}$ is usually sufficient for almost all rainfall to infiltrate even with finer resolutions, which leaves $P^{i m p}$ as the dominant factor. With finer resolutions, models have more complex overland flow paths, which leads to lower $P^{i m p}$ and thus results in more infiltration and a decrease in both total flow and peak flow. However, for heavy rainfall events when the rainfall intensity exceeds infiltration capacity, larger $P^{p}$ means more infiltration; at the same time the runoff from impervious areas unconnected to the drainage system can also contribute to discharge because of the absence of infiltration capacity, and the dominant factor thus changes from $P^{i m p}$ to $P^{p}$. This explains why the spatial resolution effects on model outputs are bidirectional for heavy and light rainfall events. Given this explanation, Kronaveter et al. (2001) noted a significant scale effect for soils with lower saturated hydraulic conductivity where scale aggregation produced more infiltration, and the divergent results of scale effects in the present literature, as mentioned in the introduction, can be reasonably explained.

However, for heavy rainfall events, the overall difference is not significant compared with the results under light rainfall conditions. On one hand, the total flow and peak flow are larger under heavy rainfall events, which may cause larger absolute errors but smaller relative errors. On the other hand, events with large rainfall amount are always associated with long duration. Especially for extreme rainfall events characterized by both extremely total rainfall amount and duration, the simulation errors of total flow, peak flow and infiltration are approximately zero, as shown by the deepest blue points (in Figure 7). To explain the results and further improve understanding of the affecting mechanism, two typical long-duration events (E160720 and E120721) with extremely large rainfall amounts were selected for analysis. As shown in Figure 8, the infiltration processes were compared between the 10-m and 250-m model. It is demonstrated that when the soil is not saturated, i.e., for the early period of events or when small rainfall intensity lasts for a long time, the 10-m model shows more infiltration. Otherwise, the coarser model shows more infiltration because of the larger $P^{p}$. That is the reason why differences in total infiltration are not significant for some heavy events.

\subsection{Parameter Upscaling}

Figure 9 shows the relationship between $P^{i m p}$ and $P_{r}$ at different spatial resolutions by calculation and fitting. At a specific resolution, $P^{i m p}$ trends to decrease with increasing $P_{r}$. For $P^{i m p}$ s at different resolutions, they can be equalized by adjusting $P_{r}$. As assumed in the study, $P_{r}$ is set to 0 for the finest resolution model, i.e., $10 \mathrm{~m}$, which indicates that the grids are so detailed that $P_{r}$ use is not needed to describe the flow paths. To keep $P^{i m p}$ steady, $P_{r}$ values can be set to $0.11,0.24,0.35$ and 0.38 for 30 -m, $50-\mathrm{m}, 100-\mathrm{m}$, and $250-\mathrm{m}$ resolution respectively. The power function is a very good approximation of the relationship between the calculated $P^{i m p}$ and $P_{r}$, where the constant term reflects the magnitude of the initial $P^{i m p}$ corresponding to zero $P_{r}$ value and the exponent term is related to the complexity of overland flow paths, with larger values implying a simpler routing path.

Figure 10 shows the change of Manning's coefficient $(n)$ at different spatial resolutions for the eight typical rainfall events selected, including observed and designed events. In contrast with observed events, designed events are assigned with the same rainfall temporal pattern, aiming to demonstrate the influence of the single variable (i.e. rainfall amount) on setting $n$ values. The black solid lines are the upper and lower boundaries of Manning's coefficient, corresponding to the $P^{p}{ }_{\max }$ and $P^{p}{ }_{\min }$ respectively, which limits $n$ values in a reasonable range. The varying rainfall conditions are described by the maximum averaged rain intensity within $1.5 \mathrm{~h}$. In general, Manning's coefficient decreases with rainfall intensity. However, it is influenced by the antecedent moisture conditions at the same time, which results in the anomaly shown as the blue dotted line in Figure 10 . The curves showing the relationship between Manning's coefficient and spatial resolution under different rainfall conditions divide the feasible region of the $n$ value into several intervals, which provides more specific reference for the value of Manning's coefficient in addition to the theoretical range, adapting to different rainfall scenarios. Combined with specific $P_{r}$ s, the parameter upscaling approach is obtained.

Finally, the upscaling approach was applied to three typical rainfall events, including a light event (E170605), a heavy event (E170714), and an extreme rainfall event (E160720) characterized by both extreme large rainfall amount and long duration. The performance of the upscaling approach is shown in Figure 11. Sub-Figures (a1), (b1) and (c1) present the results without the upscaling approach; significant differences exist among simulated river flows of different resolutions, especially in peak flows. Sub-Figures (a2), (b2), and (c2) show the results with the upscaling approach; river flows of different resolutions closely converge, with the bias indicators maximum PE and RPE reduced from $-2.257 \mathrm{~m}^{3} / \mathrm{s}$ to $0.203 \mathrm{~m}^{3} / \mathrm{s}$ and from $67 \%$ to $9.6 \%$, respectively. Moreover, NSE coefficients are improved from 0.78 to 0.98 , which demonstrates the reliability and effectiveness of the approach.

\section{CONCLUSIONS}

To understand and represent the scale effects in modeling, a grid-based urban hydrological model (REDUS) was applied to a 3.3 $\mathrm{km}^{2}$ urban catchment. Simulations were performed for 18 observed rainfall events, with 5 different resolutions ranging from 10 $\mathrm{m}$ to $250 \mathrm{~m}$. The main findings include:

1. The routing features can be quantitatively well described by the two parameters, $P^{i m p}$ and $P^{p}$, related to impervious and pervious areas respectively. An increase in spatial resolution causes decreases in these two parameters, which results in different effects on simulation results. Decreased $P^{i m p}$ leads to a reduced runoff, and decreased $P^{p}$ leads to increased runoff. 
2. Routing features are identified as the crucial cause of infiltration discrepancies at varying spatial resolutions, which then yield significant bidirectional scale effects on river discharge. For heavy rainfall events, simulated total runoff and peak flow decrease with coarser spatial resolution, which is dominated by $P^{p}$. However, the results are opposite for light rainfall events, which are dominated by $P^{i m p}$. The exchange of dominant factors is attributed to the comparative role played by infiltration capacity and rainfall intensity.

3. The two key model parameters (the Manning's coefficient $(n)$ of pervious areas and the percent routed $\left(P_{r}\right)$ of impervious areas) strongly depend on spatial resolution, and the variation of these two parameters at different spatial resolutions are well explained by the routing features $P^{i m p}$ and $P^{p}$. Therefore, a parameter upscaling approach is proposed, i.e. to derive the parameters for coarser resolution based on the underlying surface features that are directly obtained from the finest resolution data. This approach also demonstrated that the parameters are physically transferable among different resolutions to obtain results with good consistency.

In the context of climate change and urbanization, flooding prediction deserves increased attention. Given the differences in the characterization of hydrologic features by varying resolutions, scale-based parameter setting is highly suggested for coarse models, instead of forcing the model to give better performance by conventional methods of calibration. Despite the pronounced basin scale-dependence of the impacts of scale effect on hydrological response, the essence of scale effects on surface routing will be unchanged, i.e. finer resolutions result in more detailed depiction of the study area and lead to more complicated routing. This study exactly grasps the quantitative relationship between spatial scale and routing features, and further proposes a parameter upscaling approach that can be applied to catchments of different sizes, providing a practical way to solve the scaling issue. The physically based parameters transfer among different spatial resolutions enables accurate and efficient simulations required by real time flooding forecasting and land-atmosphere coupling, while fully taking the advantages of detailed surface information.

ACKNOWLEDGMENTS, SAMPLES, AND DATA

This work was funded by National Natural Science Foundation of China (51679119) and the National Key Research and Development Program of China (2018YFA0606002). The authors thank the Northwest Institute of Eco-Environment and Resources for providing the land cover data. The authors also thank Tsinghua University for providing pipe data. The data used to produce the results of this paper are freely available online at http://www.urbanhydromet.org/col.jsp?id=112\&.

Nomenclature

\begin{tabular}{|c|c|}
\hline $\boldsymbol{A}$ & Area of a grid $\left(\mathrm{m}^{2}\right)$ \\
\hline Pimp, $P p$ & Two physical parameters - routing features for impervious and pervious areas, respectively. (--, m) \\
\hline$d$ & Water depth (m) \\
\hline$d s$ & Depth of depression storage (m) \\
\hline $\boldsymbol{I}$ & Infiltration $\left(\mathrm{m}^{3}\right)$ \\
\hline Imax & Maximum rainfall intensity $(\mathrm{mm} / \mathrm{hr})$ \\
\hline $\boldsymbol{L}$ & Length of the overland flow in a grid $(\mathrm{m})$ \\
\hline$n$ & Manning's coefficient \\
\hline$n^{0}$ & Original Manning's coefficient $(n)$ \\
\hline$N S E$ & Nash-Sutcliffe efficiency coefficient \\
\hline $\boldsymbol{P}$ & Rainfall $\left(\mathrm{m}^{3}\right)$ \\
\hline$P F$ & Peak flow $\left(\mathrm{m}^{3} / \mathrm{s}\right)$ \\
\hline $\boldsymbol{P}_{\boldsymbol{r}}$ & Percent routed \\
\hline$q$ & Flow rate per unit of surface area $(\mathrm{m} / \mathrm{s})$ \\
\hline$Q_{o}$ & Flow out of other outlets $\left(\mathrm{m}^{3}\right)$ \\
\hline$Q_{r}$ & Flow out of river $\left(\mathrm{m}^{3}\right)$ \\
\hline REI & Relative error of infiltration \\
\hline REP & Relative error of peak flow \\
\hline$R E T$ & Relative error of total flow \\
\hline$S$ & Sub-catchment slope \\
\hline$S_{d}$ & Amount of water stored in the drainage system $\left(\mathrm{m}^{3}\right)$ \\
\hline$S_{s}$ & Amount of water stored in the surface depression $\left(\mathrm{m}^{3}\right)$ \\
\hline$T F$ & Total flow $\left(\mathrm{m}^{3}\right)$ \\
\hline $\boldsymbol{W}$ & Subcatchment feature width (m) \\
\hline
\end{tabular}


Appendix A: Hyetograph of the rainfall events used for studying the parameter upscaling scheme
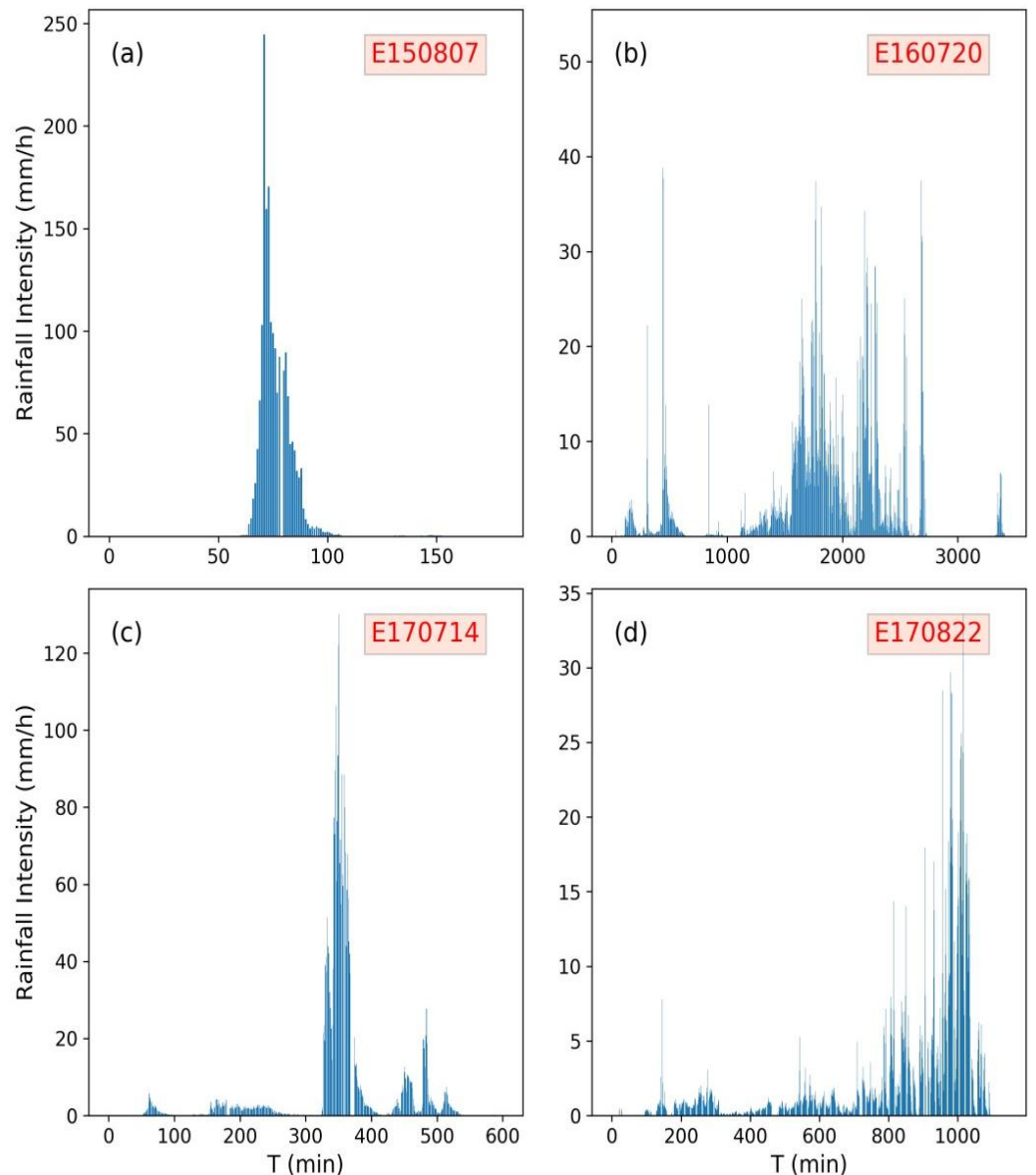

Figure A1. Hyetograph of four typical rainfall events adopted to study the parameter upscaling scheme.

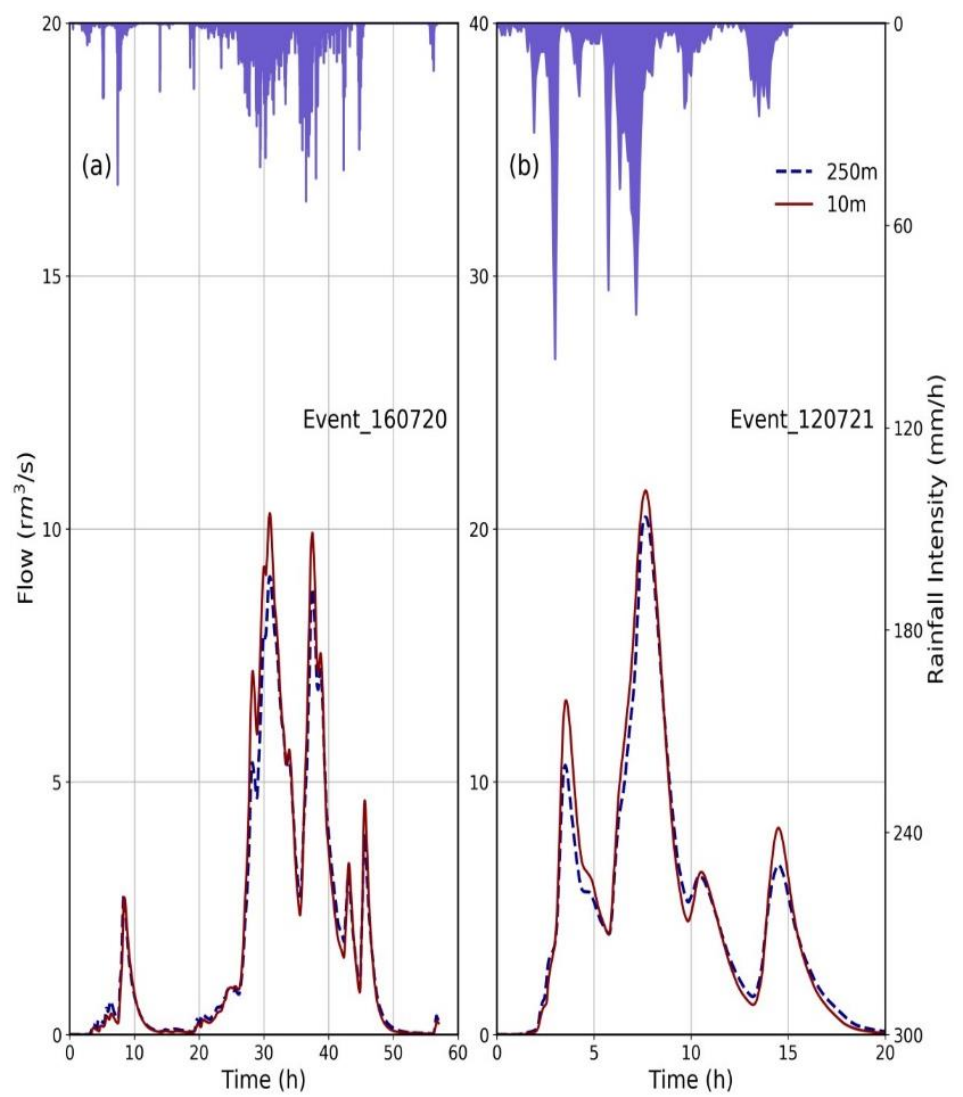

Appendix B: Hydrograph of the outlet for $10-m$ and 250-m models under two extreme rainfall events

Figure B1. Hydrograph of the outlet for 10-m and 250$\mathrm{m}$ models under two extreme rainfall events: E160720 and E120721. 


\section{Appendix C: The spatial variation of rainfall in Tsinghua University, Beijing, China.}

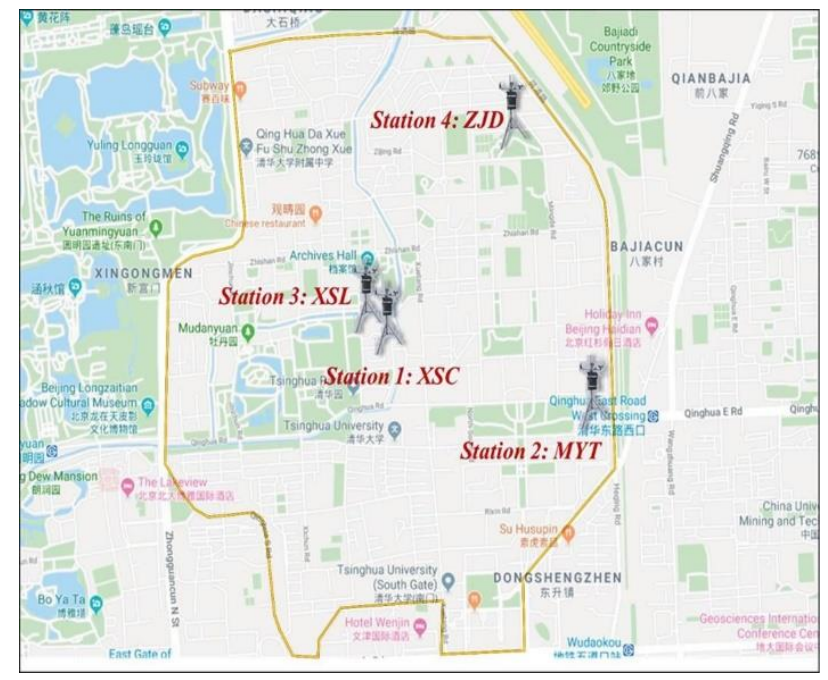

Figure C1. The spatial distribution of the four micro weather stations in the study area.

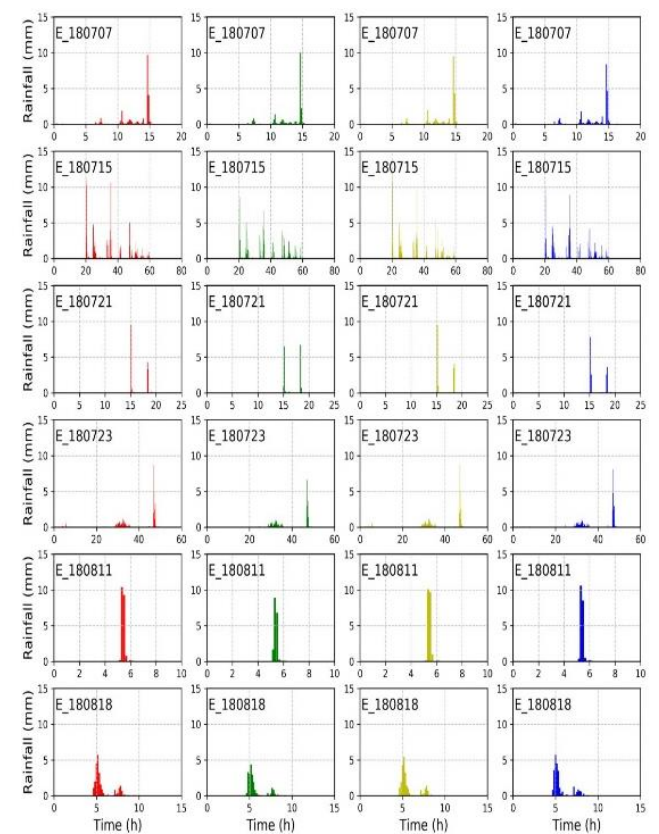

Figure C2. The hyetographs of six rainfall events measured by different micro weather stations. Red, green, yellow and blue denote station XSC, MYT, XSL and ZJD, respectively. The vertical arises donate accumulated rainfall per ten minutes.

\section{References}

Amorocho, J. (1961). "Discussion on 'Predicting storm runoff on small experimental watersheds,' by N. E. Minshall." J. Hydraul. Div., 87(HY2), 185-191.

Berne, A., Delrieu, G., Creutin, J. D., \& Obled, C. (2004). Temporal and spatial resolution of rainfall measurements required for urban hydrology. Journal of Hydrology, 299(3-4), 166179. doi:10.1016/j.jhydrol.2004.08.002

Boyd, M. J., Bufill, M. C., \& Knee, R. M. (1994). Predicting pervious and impervious storm runoff from urban drainage basins. Hydrological Sciences Journal, 39(4), 321-332. doi:10.1080/02626669409492753

Brakensiek, D. L., \& Onstad, C. A... (1977). Parameter estimation of the green and ampt infiltration equation. Water Resources Research, 13(6). doi: 10.1029/WR013i006p01009 Burns, M. J., Walsh, C. J., Fletcher, T. D., Ladson, A. R., \& Hatt, B. E. (2015). A landscape measure of urban stormwater runoff effects is a better predictor of stream condition than a suite of hydrologic factors. Ecohydrology, 8(1), 160-171. doi:10.1002/eco.1497 Cantone, J. P. (2011). Improved understanding and prediction of the hydrologic response of highly urbanized catchments through development of the illinois urban hydrologic model (iuhm) by. Water Resources Research, 47(8), 8538. doi: 10.1029/2010WR009330

Eggimann, S., Mutzner, L., Wani, O., Schneider, M. Y., Spuhler, D., Moy de Vitry, M., ... \& Maurer, M. (2017). The potential of knowing more: A review of data-driven urban water management. Environmental science \& technology, 51(5), 2538-2553.

Einfalt, T., Arnbjerg-Nielsen, K., Golz, C., Jensen, N. E., Quirmbach, M., Vaes, G., \& Vieux, B. (2004). Towards a roadmap for use of radar rainfall data in urban drainage. Journal of Hydrology, 299(3-4), 186-202. doi:10.1016/j.jhydrol.2004.08.004

Elliott, A. H., Trowsdale, S. A., \& Wadhwa, S. (2009). Effect of aggregation of on-site stormwater control devices in an urban catchment model. Journal of Hydrologic Engineering, 14(9), 975-983. doi: 10.1061/(ASCE)HE.1943-5584.0000064

Fang, Z., Bogena, H., Kollet, S., \& Vereecken, H. (2016). Scale dependent parameterization of soil hydraulic conductivity in 3d simulation of hydrological processes in a forested headwater catchment. Journal of Hydrology, 536, 365-375. doi: 10.1016/j.jhydrol.2016.03.020

Gangodagamage, C., Belmont, P., \& Foufoula-Georgiou, E. (2011). Revisiting scaling laws in river basins: new considerations across hillslope and fluvial regimes. Water Resources Research, 47(7), W07508. doi:10.1029/2010WR009252

Ghosh, I., \& Hellweger, F. L. (2011). Effects of spatial resolution in urban hydrologic simulations. Journal of Hydrologic Engineering, 17(1), 129-137. doi:10.1061/(ASCE)HE.1943-5584.0000405

Goldstein, A., Foti, R., \& Montalto, F. (2016). Effect of spatial resolution in modeling stormwater runoff for an urban block. Journal of Hydrologic Engineering, 21(11), 06016009. doi:10.1061/(ASCE)HE.1943-5584.0001377

Goodrich, D. C., Faurès, J. M., Woolhiser, D. A., Lane, L. J., \& Sorooshian, S. (1995). Measurement and analysis of small-scale convective storm rainfall variability. Journal of hydrology, 173(1-4), 283-308. doi:10.1016/0022-1694(95)02703-R

Green, W. H., and Ampt, C. A. (1911). "Studies on soil physics-1. The flow of air and water through soils." J. Agric. Sci., 4(1), 1-24.

Guan, M., Sillanpää, N., \& Koivusalo, H. (2015). Modelling and assessment of hydrological changes in a developing urban catchment. Hydrological Processes, 29(13), 2880-2894. doi:10.1002/hyp.10410

Hwang, J., Rhee, D. S., \& Seo, Y. (2017). Implication of Directly Connected Impervious Areas to the Mitigation of Peak Flows in Urban Catchments. Water, 9(9), 696. doi:10.3390/w9090696

Ichiba, A. (2016). X-band radar data and predictive management in urban hydrology (Doctoral dissertation, Université Paris-Est). https://halhprints.archives-ouvertes.fr/HMCO/tel01437464v1 
Ichiba, A., Gires, A., Tchiguirinskaia, I., Schertzer, D., Bompard, P., \& Ten Veldhui, M. C. (2018). Scale effect challenges in urban hydrology highlighted with a distributed hydrological model. Hydrology \& Earth System Sciences, 22(1). doi:10.5194/hess-22-3312018

Kocyigit, M. B., Akay, H., \& Yanmaz, A. M. (2017). Effect of watershed partitioning on hydrologic parameters and estimation of hydrograph of an ungauged basin: a case study in Gokirmak and Kocanaz, Turkey. Arabian Journal of Geosciences, 10(15). doi: 10.1007/s12517-0173132-8

Krebs, G., Kokkonen, T., Valtanen, M., Koivusalo, H., \& Setälä, H. (2013). A high resolution application of a stormwater management model (SWMM) using genetic parameter optimization. Urban Water Journal, 10(6), 394-410. doi:10.1080/1573062X.2012.739631

Krebs, G., Kokkonen, T., Valtanen, M., Setälä, H., \& Koivusalo, H. (2014). Spatial resolution considerations for urban hydrological modelling. Journal of hydrology, 512, 482-497. doi:10.1016/j.jhydrol.2014.03.013

Kronaveter, L., Shamir, U., \& Kessler, A. (2001). Water-sensitive urban planning: modeling on-site infiltration. Journal of Water Resources Planning and Management, 127(2), 78-88. doi:10.1061/(ASCE)0733-9496(2001)127:2(78)

Leandro, J., Schumann, A., \& Pfister, A. (2016). A step towards considering the spatial heterogeneity of urban key features in urban hydrology flood modelling. Journal of Hydrology, 535, 356-365. doi:10.1016/j.jhydrol.2016.01.060

Li, D., Wang, X., Xie, Y., Chen, J., Tian, Y., Chen, W., \& Cai, X. (2016). A multi-level and modular model for simulating the urban flooding and its application to Tianjin City. Natural Hazards, 82(3), 1947-1965. doi:10.1007/s110

Lyu, H., Ni, G., Cao, X., Ma, Y., \& Tian, F. (2018). Effect of temporal resolution of rainfall on simulation of urban flood processes. Water, 10(7), 880. doi:10.3390/w10070880

Marie-Claire, T. V., Zhengzheng, Z., Long, Y., Shuguang, L., \& James, S.. (2018). The role of storm scale, position and movement in controlling urban flood response. Hydrology and Earth System Sciences, 22(1), 417-436. doi: 10.5194/hess-22-417-2018

Mcpherson, M. B., \& Schneider, W. J. . (1974). Problems in modeling urban watersheds. Water Resources Research, 10(3).doi: 10.1029/WR010i003p00434

Meierdiercks, K. L., Smith, J. A., Baeck, M. L., \& Miller, A. J. (2010). Analyses of Urban

Drainage Network Structure and its Impact on Hydrologic Response 1. JAWRA Journal of the American Water Resources Association, 46(5),

932-943. doi: 10.1111/j.17521688.2010.00465.x

Metcalf \& Eddy, I., Univ. of Florida and Water Resources Engineers, Inc. (1971). "Storm water management model volume 1-Final Report." Rep. No. 11024 DC07/71, Environmental Protection Agency, WA, DC, 63-76.

Minshall, N. E. (1960). Predicting storm runoff on small experimental watersheds. Journal of the Hydraulics Division, 86(8), 17-38.

Nash, J. E., \& Sutcliffe, J. V. (1970). River flow forecasting through conceptual models part I - A discussion of principles. Journal of Hydrology, 10(3), 282-290. doi: 10.1016/00221694(70)90255-6

Pan, A., Hou, A., Tian, F., Ni, G., \& Hu, H. (2011). Hydrologically enhanced distributed urban drainage model and its application in Beijing city. Journal of Hydrologic Engineering, 17(6), 667-678. doi: 10.1061/(ASCE)HE.1943-5584.0000491

Park, S. Y., Lee, K. W., Park, I. H., \& Ha, S. R. (2008). Effect of the aggregation level of surface runoff fields and sewer network for a SWMM simulation. Desalination, 226(1-3), 328-337. doi: 10.1016/j.desal.2007.02.115

Passalacqua, P., Tarolli, P., \& Foufoula-Georgiou, E. (2010). Testing space-scale methodologies for automatic geomorphic feature extraction from lidar in a complex mountainous landscape. Water Resources Research, 46(11), 208-217. doi: 10.1029/2009WR008812

Petrucci, G., \& Bonhomme, C. (2014). The dilemma of spatial representation for urban hydrology semi-distributed modelling: Trade-offs among complexity, calibration and geographical data. Journal of Hydrology, 517, 997-1007. doi: 10.1016/j.jhydrol.2014.06.019

Rodriguez, F., Andrieu, H., \& Morena, F. (2008). A distributed hydrological model for urbanized areas-Model development and application to case studies. Journal of Hydrology, 351(3-4), 268-287. doi: 10.1016/j.jhydrol.2007.12.007

Rosa, D. J., Clausen, J. C., \& Dietz, M. E. (2015). Calibration and verification of SWMM for low impact development. JAWRA Journal of the American Water Resources Association, 51(3), 746-757. doi: 10.1111/jawr.12272

Rossman L A., (2015). Storm water management model reference manual: volume I-hydrology (Revised) [M] . Cincinnati: US Environmental Protection Agency.

Sahoo, S. N., \& Sreeja, P. (2013). Role of rainfall events and imperviousness parameters on urban runoff modelling. ISH Journal of Hydraulic Engineering, 19(3), 329-334. doi: 10.1080/09715010.2013.819706

Salvadore, E., Bronders, J., \& Batelaan, O. (2015). Hydrological modelling of urbanized catchments: A review and future directions. Journal of Hydrology, 529(529), 62-81. doi: 10.1016/j.jhydrol.2015.06.028

Schoener, G. (2017). Urban Runoff in the US Southwest: Importance of Impervious Surfaces for Small-Storm Hydrology. Journal of Hydrologic Engineering, 23(2), 05017033. doi: 10.1061/\%28ASCE\%29HE.1943-5584.000161

Singh, V. P. (1997). Effect of spatial and temporal variability in rainfall and watershed characteristics on stream flow hydrograph. Hydrological processes, 11(12), 1649-1669. doi: 10.1002/(SICI)1099-1085(19971015)11:12<1649::AID-HYP495>3.0.CO;2-1

Sun, N., Hall, M., Hong, B., \& Zhang, L. (2012). Impact of SWMM catchment discretization: case study in Syracuse, New York. Journal of Hydrologic Engineering, 19(1), 223-234. doi: 10.1061/(ASCE)HE.1943-5584.0000777

Umakhanthan, K. and Ball, J.E., 2005. Rainfall models for catchment simulation. Australasian Journal of Water Resources, 9 (1), $55-67$.

Warsta, L., Niemi, T. J., Taka, M., Krebs, G., Haahti, K., Koivusalo, H., \& Kokkonen, T. (2017). Development and application of an automated subcatchment generator for SWMM using open data. Urban water journal, 14(9), 954-963. doi: $10.1080 / 1573062 X .2017 .1325496$

Warwick, J. J., \& Litchfield, J. (1993). Impact of spatial and temporal data limitations on the modeling of runoff quantity and quality. In Water Management in the'90s: A Time for Innovation (pp. 862-865).

Wood, E. F., Sivapalan, M., Beven, K., \& Band, L. (1988). Effects of spatial variability and scale with implications to hydrologic modeling. Journal of hydrology, 102(1-4), 29-47. doi: 10.1016/0022-1694(88)90090-X

Wright, D. B. , Smith, J. A. , \& Baeck, M. L. . (2014). Flood frequency analysis using radar rainfall fields and stochastic storm transposition. Water Resources Research, 50(2), 15921615. doi:10.1002/2013WR014224

Wright, D. B., Smith, J. A., Villarini, G., \& Baeck, M. L. (2014). Long-Term High-Resolution Radar Rainfall Fields for Urban Hydrology†. Journal

of The American Water Resources Association, 50(3), 713-734. doi: 10.1111/jawr.12139

Yang, G., Bowling, L. C., Cherkauer, K. A., \& Pijanowski, B. C. (2011). The impact of urban development on hydrologic regime from catchment to basin scales. Landscape and Urban Planning, 103(2), 237-247. doi:10.1016/j.landurbplan.2011.08.003 
Yang, L., Smith, J. A., Baeck, M. L., \& Zhang, Y. (2016). Flash flooding in small urban watersheds: storm event hydrologic response. Water Resources Research, 52(6), 45714589. doi:10.1002/2015WR018326

Yang, L., Tian, F., \& Niyogi, D. (2015). A need to revisit hydrologic responses to urbanization by incorporating the feedback on spatial rainfall patterns. Urban Climate, 12, 128-140. doi: 10.1016/j.uclim.2015.03.001

Yang, P., Ren, G., Hou, W., \& Liu, W. (2013). Spatial and diurnal characteristics of summer rainfall over beijing municipality based on a highdensity aws dataset. International Journal of Climatology, 33(13), 2769-2780.

Zaghloul, N. A. (1981). SWMM model and level of discretization. Journal of the Hydraulics Division, 107(11), 1535-1545.

Zhang, W., \& Montgomery, D. R. (1994). Digital elevation model grid size, landscape representation, and hydrologic simulations. Water resources research, 30(4), 1019-1028. doi: 10.1029/93WR03553

Zhou, Z., Smith, J. A., Yang, L., Baeck, M. L., Chaney, M., Ten Veldhuis, M. C., \& Liu, S.

(2017). The complexities of urban flood response: Flood frequency analyses for the Charlotte metropolitan region. Water Resources Research, 53(8), 7401-7425. doi:10.1002/2016WR019997.

Table 1. Main characteristics of the 18 rainfall events selected to perform the spatial scale effect investigations. Imax is the maximum rainfall intensity recorded in $\mathrm{mm} / \mathrm{h}$ over 1 minute. ${ }^{*}$ indicates the events used to study the parameter upscaling scheme.

\begin{tabular}{|c|c|c|c|c|}
\hline Event & $\begin{array}{l}\text { Rainfall duration } \\
\qquad(\mathrm{h})\end{array}$ & $\begin{array}{l}\text { Total depth } \\
(\mathrm{mm})\end{array}$ & $\begin{array}{l}\operatorname{Imax} \\
(\mathrm{mm} / \mathrm{h})\end{array}$ & $\begin{array}{l}\text { Average depth } \\
(\mathrm{mm} / \mathrm{h})\end{array}$ \\
\hline E120721 & 17 & 184.5 & 99.6 & 10.9 \\
\hline E140831 & 7 & 58.9 & 124.8 & 8.4 \\
\hline E150717 & 78 & 68.7 & 82.3 & 0.9 \\
\hline E150727 & 14 & 28.1 & 200.4 & 2.0 \\
\hline E150807 * & 3 & 30.6 & 244.6 & 10.2 \\
\hline E160720 * & 57 & 196.3 & 52.9 & 3.4 \\
\hline E160725 & 16 & 7.0 & 28.2 & 0.4 \\
\hline E160728 & 3 & 8.5 & 29.0 & 2.8 \\
\hline E160908 & 3 & 19.9 & 101.9 & 6.6 \\
\hline E170605 & 20 & 7.8 & 16.4 & 0.4 \\
\hline E170621 & 59 & 97.0 & 62.1 & 1.6 \\
\hline E170704 & 7 & 15.5 & 25.6 & 2.2 \\
\hline E170714 * & 10 & 54.8 & 130.2 & 5.5 \\
\hline E170721 & 6 & 28.7 & 81.8 & 4.8 \\
\hline E170802 & 10 & 10.5 & 32.7 & 1.0 \\
\hline E170808 & 3 & 5.5 & 34.5 & 1.8 \\
\hline E170812 & 7 & 29.0 & 69.7 & 4.1 \\
\hline E170822 * & 19 & 39.9 & 33.6 & 2.1 \\
\hline
\end{tabular}

Table 2. Calibrated value of parameters related to different land covers. $n$ and $d_{s}$ are the Manning's coefficient and the depth of depression storage, respectively.

\begin{tabular}{cccccc}
\hline & & \multicolumn{3}{c}{$n$} & \multicolumn{2}{c}{$d s(\mathrm{~mm})$} \\
\cline { 3 - 6 } Land cover & Imperviousness (\%) & Impervious & Pervious & Impervious & Pervious \\
\hline Tree & 0 & - & 0.3 & - & 8 \\
Shrub & 0 & - & 0.2 & - & 6 \\
Grass & 0 & - & 0.15 & - & 4 \\
Water & 100 & - & - & - & - \\
Road & 100 & 0.013 & - & 2 & - \\
Pavement & 80 & 0.015 & 0.15 & 2 & 2 \\
Building & 100 & 0.011 & - & 1 & - \\
\hline
\end{tabular}

Table 3. Calibrated value of parameters related to soil infiltration and drainage system.

$\begin{array}{lc}\text { Parameter } & \text { Calibrated value } \\ \text { Suction Head }(\mathrm{m}) & 250 \\ \text { Conductivity (mm/h) } & 1 \\ \text { Initial Deficit (frac.) } & 0.47 \\ \text { Roughness (Road) } & 0.011 \\ \text { Roughness (Sewer) } & 0.012 \\ \text { Roughness (River) } & 0.013\end{array}$



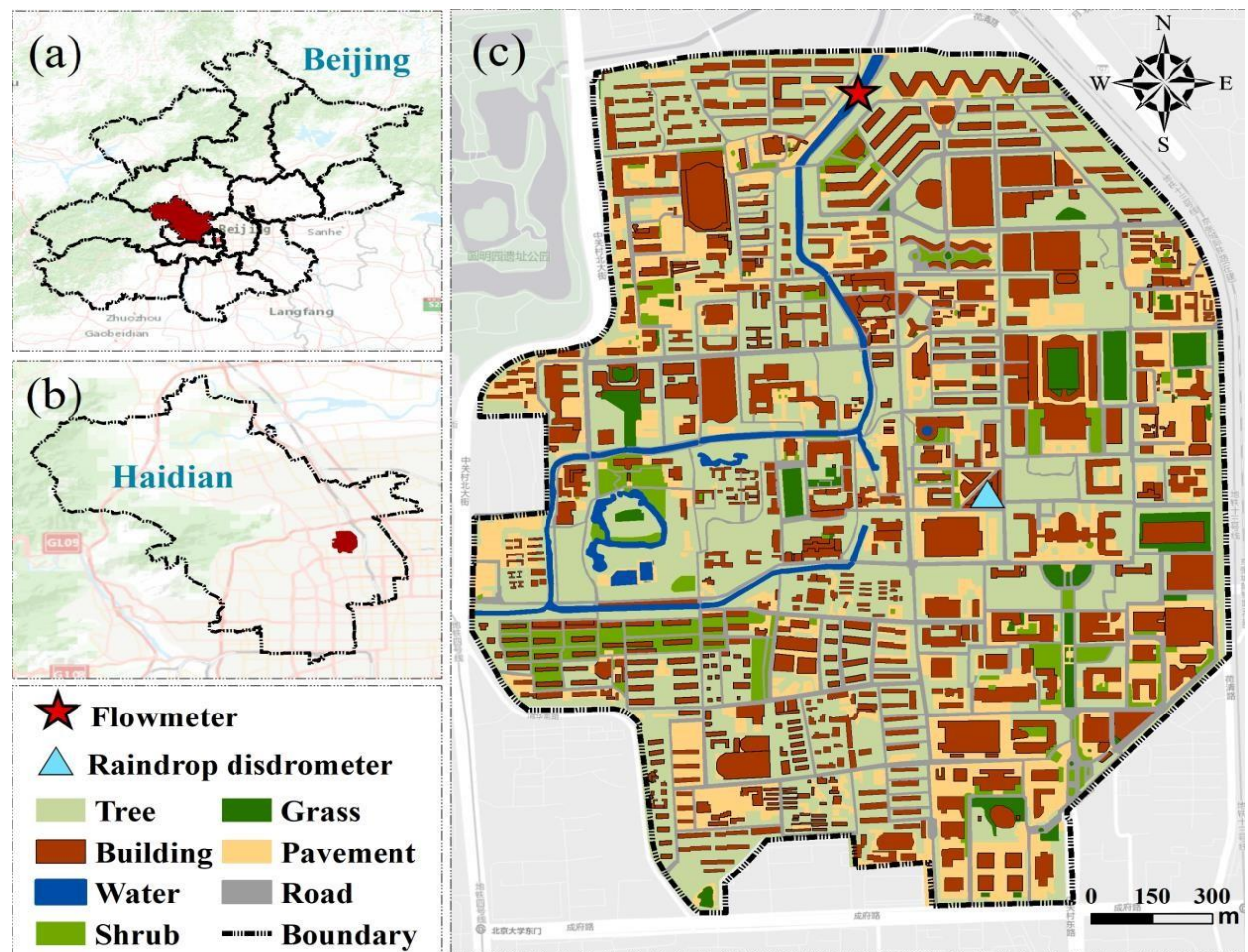

Figure 1. (a) Location of the Haidian District in Beijing; (b) location of the study area in the Haidian District; (c) location of flowmeter and raindrop disdrometer and land cover in the study area

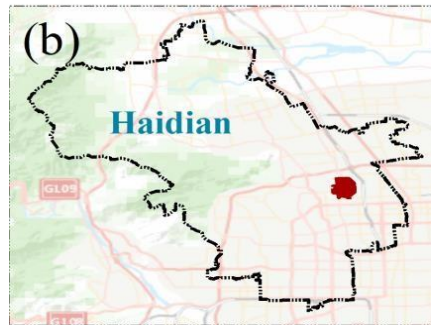

\section{خै Flowmeter}

$\triangle$ Raindrop disdrometer

\begin{tabular}{|c|c|}
\hline Tree & Grass \\
\hline Building & Pavement \\
\hline V & Road \\
\hline Shrub & Boundary \\
\hline
\end{tabular}
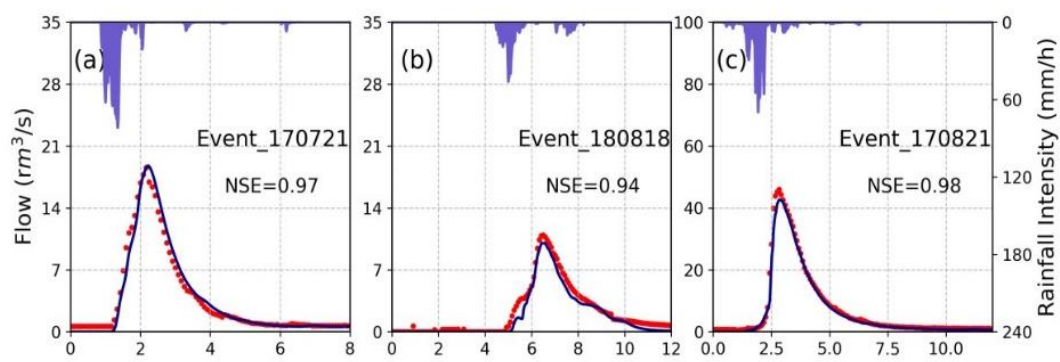

Figure 2. Results of model calibration against observed flows for different typical rainfall events. The dark blue solid line and red dots refer to the simulated and observed flows at the river outlet, respectively.
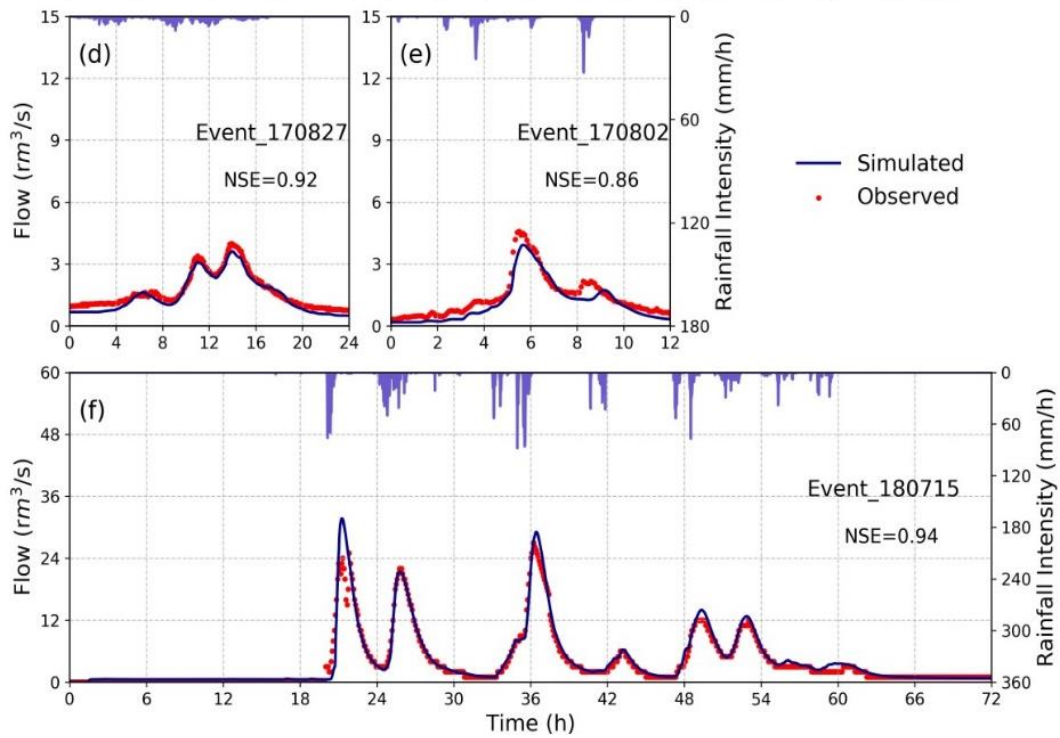

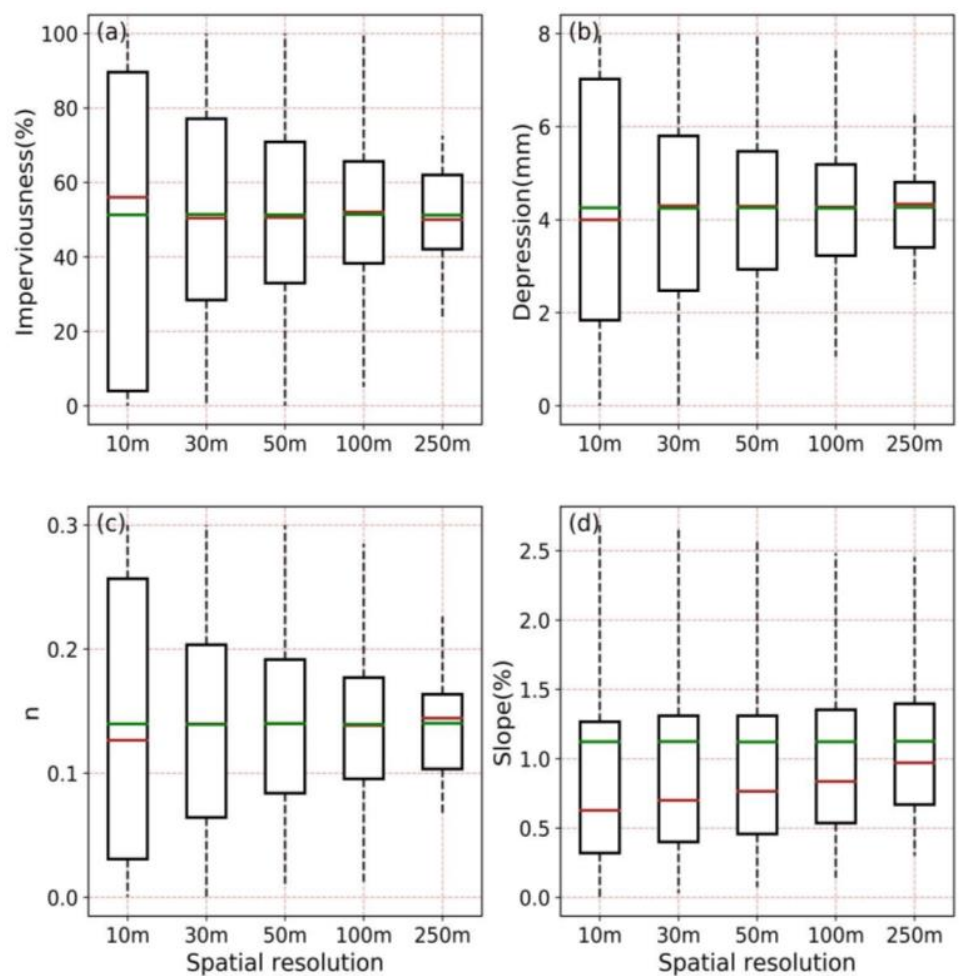

Figure 3. Overland flow process for runoff from the impervious area of a specific grid; $L_{p}$ refers to the routing length on the pervious area of the specific grid, and $L_{i m p}$ refers to the routing length on the impervious area of the specific grid. The dotted arrow denotes a part of the runoff generated from the impervious area flowing onto the pervious area of the downstream grid.

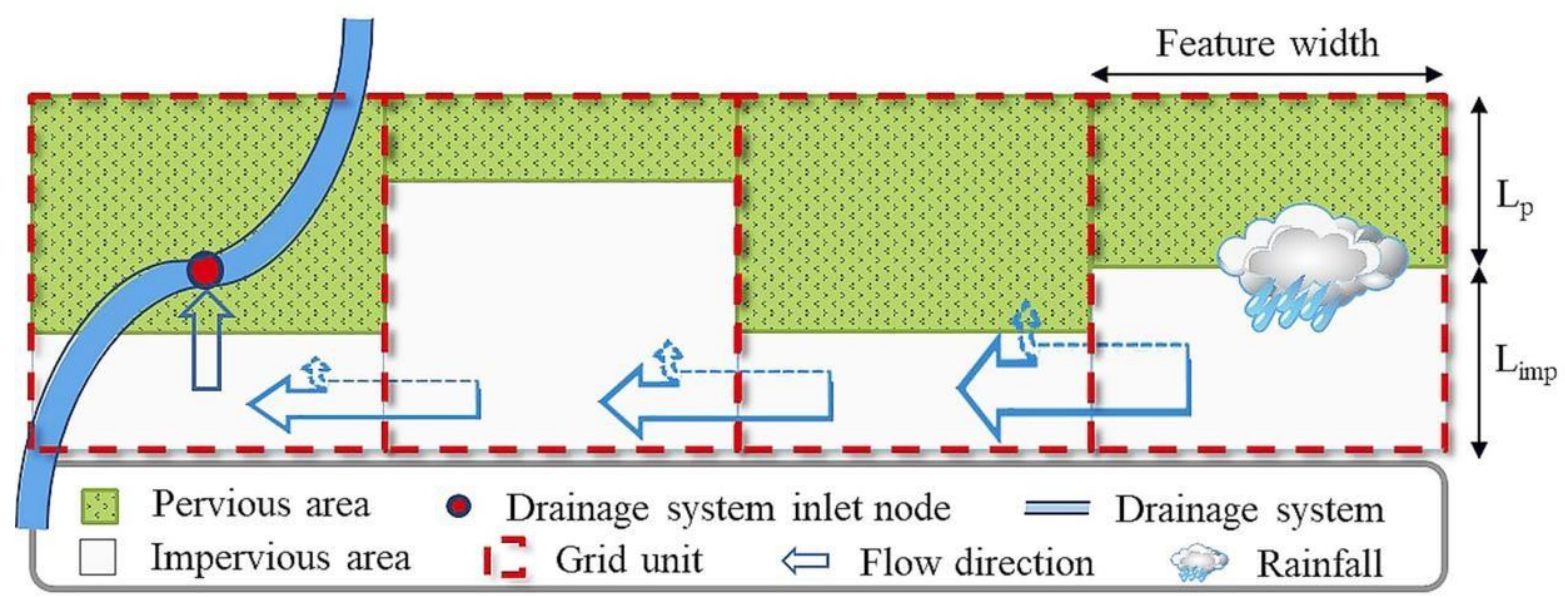

Figure 4. Statistics of key parameters at different spatial resolutions: (a) Imperviousness; (b) Depth of depression storage; (c) Manning's coefficient; (d) Underlying surface slope. Red lines represent median values, and green lines represent mean values. 


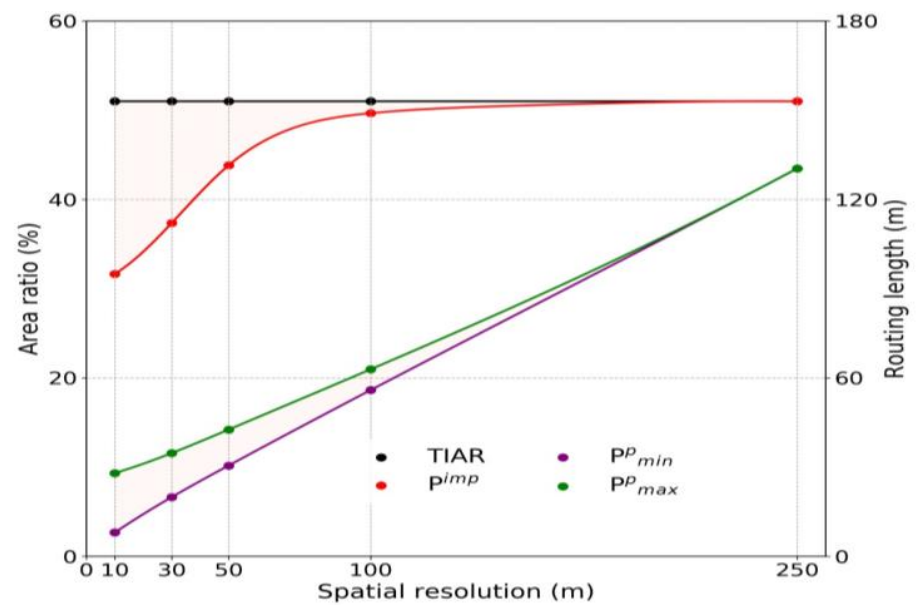

Figure 5. The variation of TIAR, $P^{i m p}, P^{p} \min$ (each grid is connected directly to the drainage system) and $P^{p}{ }_{\max }$ (overland flow along the routing path is considered) with spatial resolution.

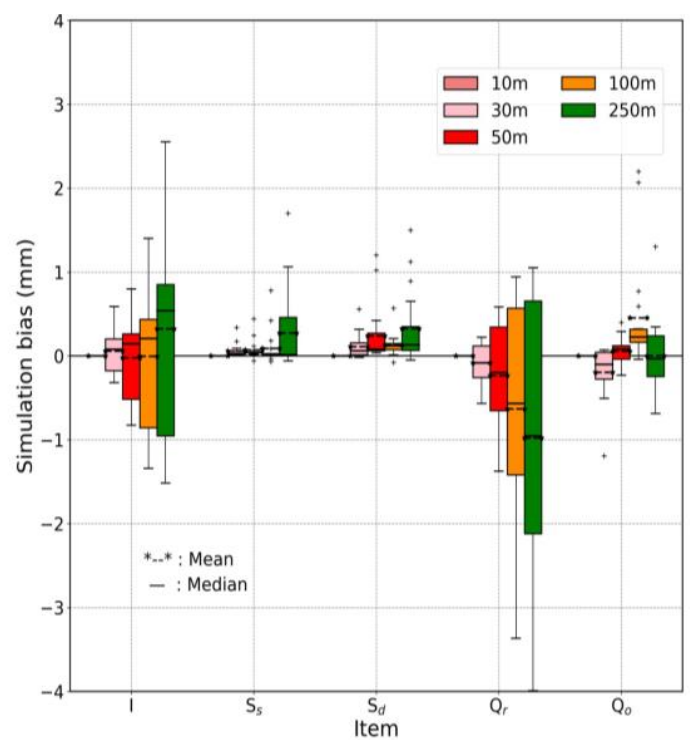

Figure 6. Comparison of water balances at different spatial scale for 18 rainfall events. $I$ denotes infiltration, $S_{s}$ denotes the amount of water stored in the surface depression, $S_{d}$ denotes the amount of water stored in the drainage system, and $Q_{r}$ and $Q_{o}$ denote the flow out of rivers and from other outlets, respectively. 

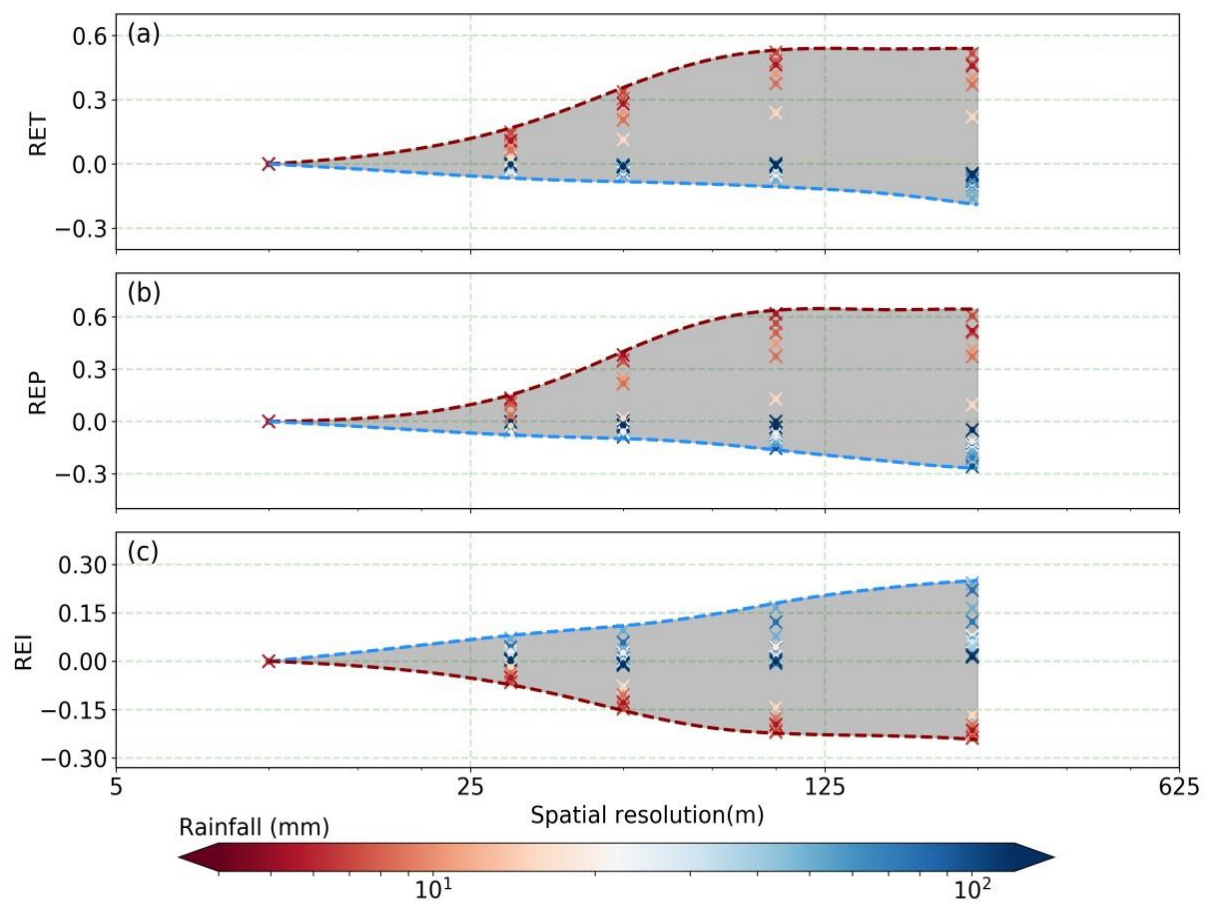

Figure 7. Effects of spatial resolution on model outputs under various rainfall events: (a) the relative error of total flow; (b) the relative error of peak flow; (c) the relative error of infiltration. The color of dots refer to the rainfall amount and the lines are the upper and lower boundaries of the results.

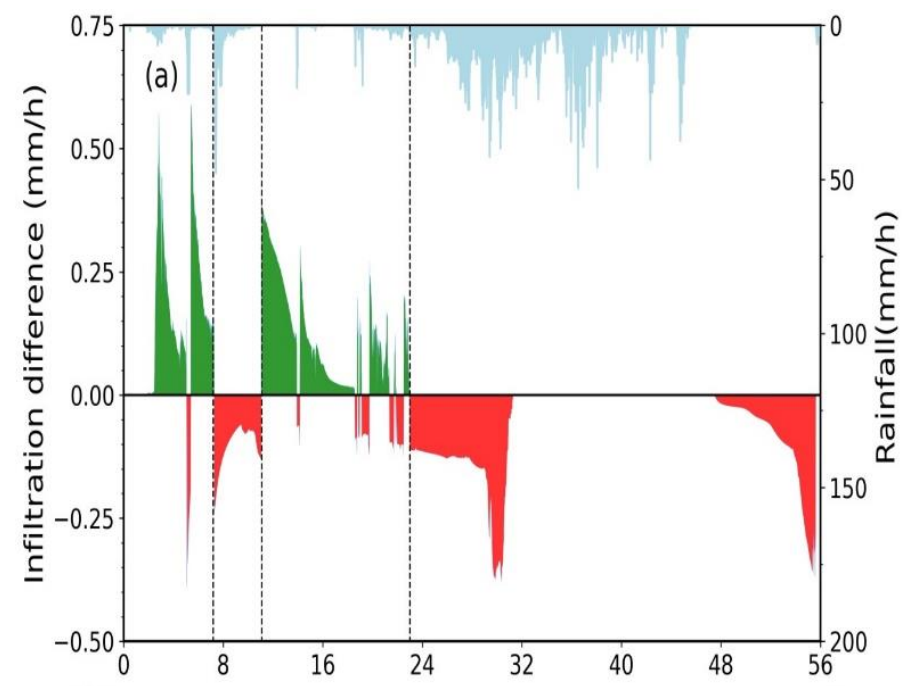

Figure 8. Comparison of infiltration processes between 10 $m$ and 250-m resolution for two extreme rainfall events with large amount and long duration: (a) E160720; (b) E120721. Infiltration difference shows the simulation results of the 10$\mathrm{m}$ resolution model minus that of the $250 \mathrm{~m}$-resolution model. Green areas indicate that the infiltration amount of $10-\mathrm{m}$ resolution is larger, whereas the red areas indicate the opposite.

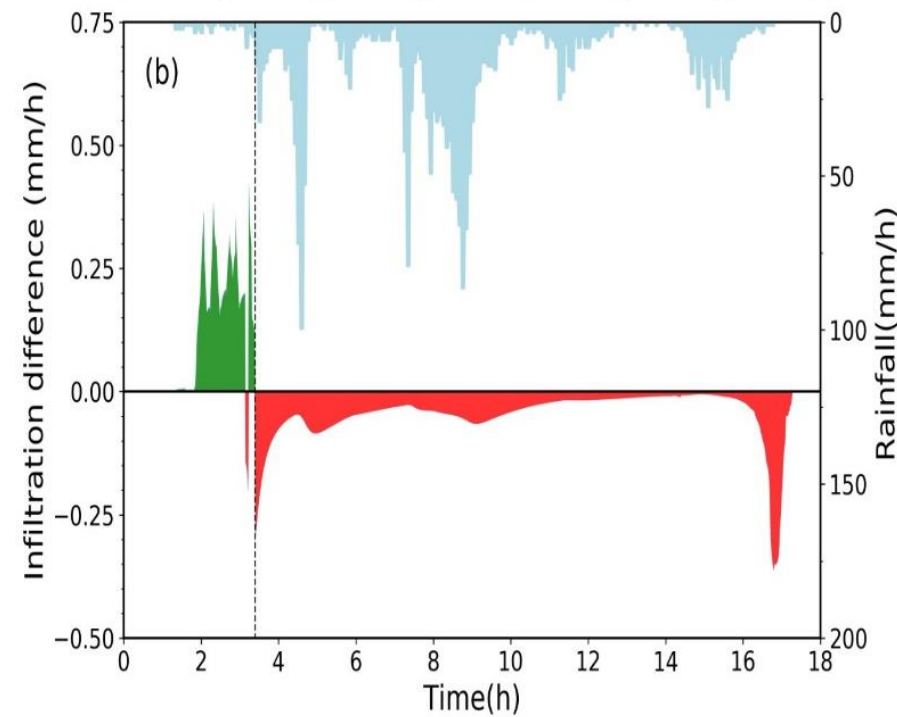




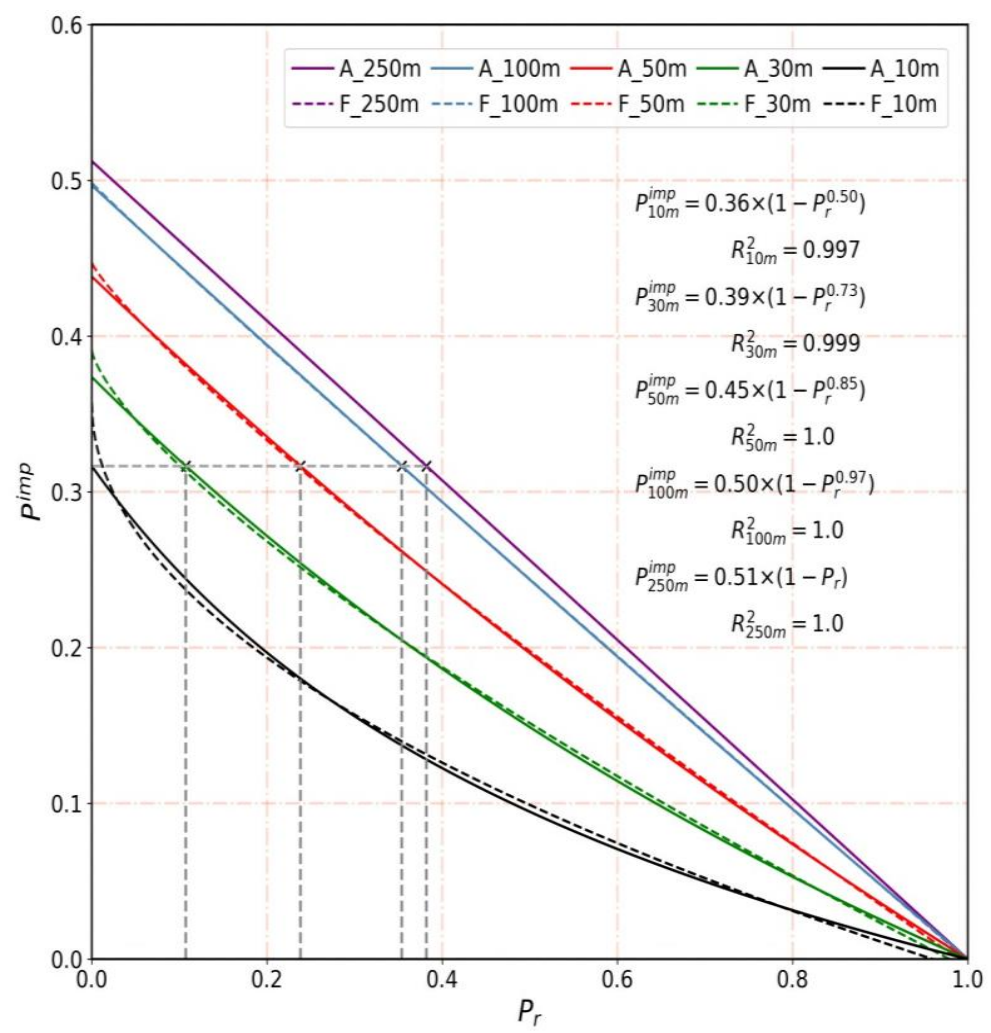

Figure 9. Actual and fitted relationship between $P^{i m p}$ and $P_{r}$ at different spatial resolutions. Solid lines represent the relationship between the calculated $P^{i m p}$ and $P_{r}$ for different resolutions, and dotted lines are the fitted curves using power functions as expressed in the upper-right corner. $R^{2}$ denotes the coefficient of determination and the subscripts (e.g. $10 \mathrm{~m}, 30 \mathrm{~m}$, etc.) denote different spatial resolutions. 

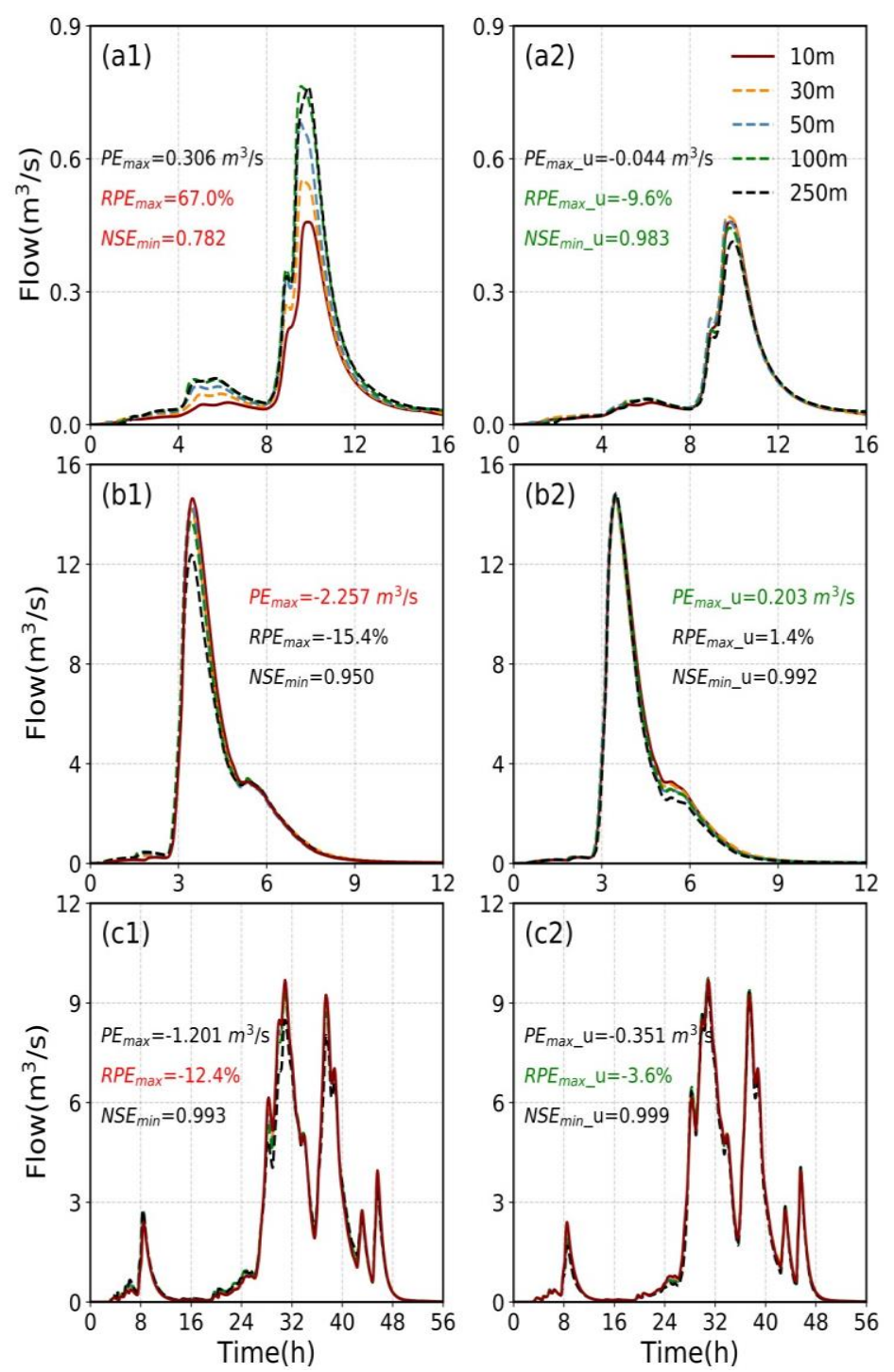

Figure 10. Parameter upscaling results for both Manning's coefficient $(n)$ and $P_{r}$ for different spatial resolutions and rainfall conditions. The left ordinate refers to the ratio of the upscaled Manning's coefficient $(n)$ from the original value $\left(n^{0}\right)$, and the right ordinate refers to the upscaled $P_{r}$. The circle (o) and plus-sign ( + ) plotted points indicate the Manning's coefficient $(n)$ under varying spatial resolutions for actual and design rainfall events, respectively, whose size shows the rainfall amount. The solid (except for the black line) and dotted lines present the relationship between Manning's coefficient $(n)$ and spatial resolution for design and actual rainfall events, respectively.

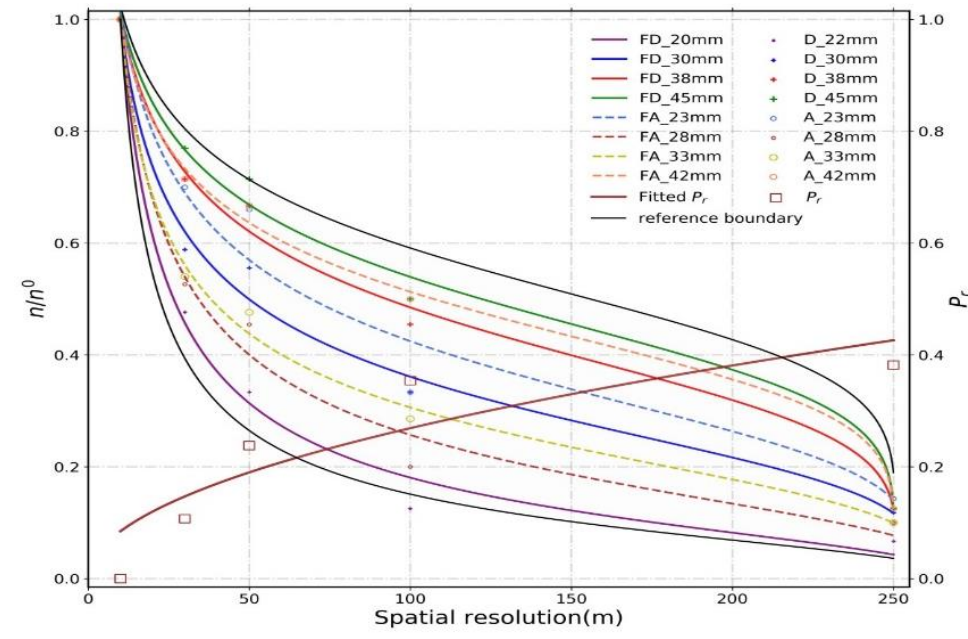

Figure 11. Performance of the upscaling approach for typical rainfall events: (a1) and (a2), light rainfall event (E170605); (b1) and (b2), heavy rainfall event (E170714); (c1) and (c2), extreme rainfall event (E160720) characterized by both extreme large rainfall amount and long duration. NSEmin denotes the minimum NSE coefficient, and $\mathrm{PE}_{\max }$ and $\mathrm{RPE}_{\max }$ denote the maximum error in peak flow and the maximum relative error in peak flow, respectively. NSEmin_u, PEmax_u, and RPEmax_u are used to present the value of corresponding indicators after adopting the upscaling approach. The value of bias indicators with significant improvement are highlighted by red and green text. 